\title{
El derecho administrativo ante la jurisprudencia de la Corte Suprema, II: Líneas y vacilaciones durante 2019
}

\author{
Alejandro Vergara Blanco \\ Profesor Titular de Derecho Administrativo \\ Pontificia Universidad Católica de Chile
}

Este texto es la continuación de un trabajo anterior sobre las líneas y vacilaciones de la jurisprudencia de la Corte Suprema en veinte temas de derecho administrativo durante la década 20082018; el que ahora se actualiza para el año calendario 2019. Sintetiza y gráfica el resultado de una investigación de un caudal de 333 sentencias de la Corte Suprema del año 2019 en veinte temas relevantes de la praxis del derecho administrativo. Su formato es sintético. Respecto de cada tema se señala: los hechos que dan origen a la conflictividad; la ratio iuris decidendi; gráficos en que queda en evidencia la conducta lineal o zigzagueante tanto de la Sala como de sus ministros y abogados integrantes; un análisis de tal comportamiento; $y$, un recuento exhaustivo de sentencias. El resultado es distinto al del primer estudio: si bien persisten algunas vacilaciones de la Corte Suprema, ahora durante 2019 se exhibe una nueva tendencia dirigida a ofrecer precedentes; existe un aumento de temas con jurisprudencia uniforme. No obstante que se mantienen alguna conducta errática de algunos de sus ministros y abogados integrantes.

Palabras clave: Jurisprudencia de derecho administrativo, Vacilaciones de la jurisprudencia, Corte Suprema, ratio iuris decidendi, comportamiento judicial.
This text is the continuation of a previous work on the lines and vacillations of the jurisprudence of the Supreme Court in twenty subjects of administrative law during the 2008-2018 decade; which is now updated for the 2019 calendar year. It synthesizes and graphs the result of an investigation of a volume of 333 Supreme Court judgments of the year 2019 on twenty relevant issues of the praxis of administrative law. Its format is synthetic. Regarding each issue, it is indicated: the facts that originated the conflict; the ratio iuris decidendi; graphics that evidences the linear or zigzagging behavior of both the Chamber as of its ministers and member attorneys; an analysis of such behavior; and, an exhaustive count of rulings. The result is different from that of the first study: although some vacillations of the Supreme Court persist, now during 2019 there is a new trend aimed at offering precedents. There is a slight increase in topics with uniform jurisprudence. However, some erratic conduct of some of its member ministers and member attorneys is maintained.

Keywords: Jurisprudence of administrative law, vacillations of jurisprudence, Supreme Court, ratio iuris decidendi, judicial behavior. 


\section{Introducción}

Esta es la continuación de un estudio anterior ${ }^{1}$; ese estudio estuvo dedicado a describir la escena jurisprudencial que dominó durante la década de 2008 a 2018 en la Corte Suprema, en veinte temas relevantes de la disciplina del derecho administrativo ${ }^{2}$. La actual investigación fue realizada sobre un caudal de 333 sentencias de la Corte Suprema del año 2019 en los mismos veinte temas del estudio anterior.

En esta continuación se mantiene el método de trabajo del anterior estudio, como se explica en la primera parte. En la segunda parte se ofrecen, en sus tres apartados, los resultados: el escenario jurisprudencial, explicado; los gráficos y el listado completo de las sentencias respectivas. Cierran el trabajo unas breves conclusiones.

\section{Primera Parte: Método de trabajo y explicación de cada uno de los veinte temas}

1. Método de trabajo: Ratio iuris decidendi idéntica en casos comparados y exhaustividad de la muestra

El método de trabajo que he seguido es el usual en toda recopilación exhaustiva de fuentes del derecho. Es el mismo de la anterior investigación, que puedo sintetizar así: Se inicia con la selección de sentencias de cada uno de los temas de la muestra (i); y, para darle validez a la muestra, cabe verificar que haya exactitud o igualdad en la ratio iuris decidendi de todos los casos que se comparan (ii).

i) selección de las sentencias. La selección de las sentencias tiene que ser el resultado de una búsqueda rigurosa (en este caso en: www.poderjudicial.cl, sin perjuicio de la ayuda inestimable que proveen otras bases de datos confiables: Thomson Reuters Chile y de vLex Chile). De esas bases se han seleccionado todas las sentencias. De este modo esta muestra permitirá ofrecer la conclusión que se busca: la linealidad o vacilación de la jurisprudencia en cada tema analizado.

\footnotetext{
1 El estudio anterior fue publicado en esta Revista N²8 (2019) Número especial, 184 pp. [alojado en el sitio web de la Revista y en los sitios en que se encuentra indexada]. Ambos estudios han sido realizados en el marco de las tareas del Observatorio jurisprudencial del Programa de Derecho Administrativo Económico de la Facultad de Derecho de la Pontificia Universidad Católica de Chile. Es el resultado de una investigación para la que he contado con la inestimable colaboración del equipo de ayudantes del Programa, quienes tuvieron a su cargo la búsqueda, selección, fichaje, confección de gráficos y elaboración del listado de sentencias. Debo agradecerles por su dedicación y meticuloso trabajo de este año a Valentina Danús, Carolina Carcamán y Maximiliano Baeza.

2 La investigación de la jurisprudencia de derecho administrativo es más amplia y cubre muchos otros temas, los que se suelen incorporar en comentarios de la jurisprudencia, en libros dedicados a la disciplina o en apuntes dirigidos a la enseñanza. Para estas publicaciones, por ahora, he elegido esos veinte temas que son harto actuales y relevantes en la praxis de la disciplina.
} 
ii) igualdad o exactitud de la materia y casos de la muestra. Ratio iuris decidendi. Si bien es verdad que cada caso es distinto (ello es obvio: suelen ser distintas las partes, las épocas o el origen del conflicto, etc.), la muestra se realizó luego de un trabajo previo de reducción de la temática de cada sentencia hasta llegar a la identificación de las respuestas jurisprudenciales a una temática muy específica, casi siempre a la interpretación de una misma norma, o conjunto de normas, o a una identidad del factum, esto es, de los hechos. Esto es, a una misma ratio iuris decidendi [=razón jurídica de la decisión]. De ahí que podemos decir que en todas las sentencias colacionadas en cada caso hay identidad de base fáctica y regulatoria: unos mismos hechos y un mismo derecho de base y, por ende, una misma (o desigual) ratio iuris decidendi para una causa igual.

Explico lo anterior pues la pretensión de este estudio es que todos los casos colacionados para cada materia sean una muestra empíricamente comparable, y así ser la base exacta de las conclusiones que se buscan: la linealidad o vacilación de la jurisprudencia.

\section{Explicación de cada tema e información que ahora se ofrece}

En la primera publicación de esta investigación cada uno de los veinte temas fue explicado considerando y ofreciendo la siguiente información: i) los hechos que dan origen al tipo de conflicto y la regulación del mismo; ii) la ratio iuris decidendi específica de cada tema; iii) el escenario jurisprudencial; y iv) gráficos de comportamiento de salas, ministros y abogados integrantes

Al respecto, en esta publicación, referida a los mismos veinte temas: omitimos completamente la información ofrecida en i) y ii), por lo que cabe remitirse a lo allí explicado; ello para evitar repeticiones en este sitio; pero, se ofrece una información enteramente nueva (como es natural) y relativa a los resultados del año 2019, en cuanto a las informaciones referidas en iii) y iv), esto es: el escenario jurisprudencial y los gráficos.

De ahí que en la Segunda Parte la explicación de cada tema esté referido al escenario jurisprudencial (comparándolo con el de la década anterior) y a los gráficos respectivos. Además, al final se agregan los listados de sentencias.

\section{Segunda Parte: Veinte temas de derecho administrativo ante la Corte Suprema (2019)}

Una advertencia cabe realizar: este es un trabajo de recopilación de sentencias sobre los veinte temas que se indican. Al realizar esta búsqueda en algunos casos no se encontró sentencia alguna referida al tema respectivo. Es el caso de los temas bajo los números 10,11, 17, 19 y 20. Si bien tales temas se mantuvieron en la numeración y subtítulos, ahí solo se consigna esta circunstancia. 
A. Escenario jurispridencial en cada tema

I. Conflictos durante el procedimiento administrativo

1. Cómputo de plazos durante la tramitación del procedimiento administrativo Escenario jurisprudencial anterior (2008-2018)

Desde el 2011 a la actualidad ha sido uniforme, aplicando la regla del artículo 25 de la LBPA.

\section{Escenario jurisprudencial 2019}

a) Conducta de la sala. La jurisprudencia de la Tercera Sala ha sido uniforme durante 2019 en cuanto a la aplicación del artículo 25 de la LBPA para el cómputo de plazos durante la tramitación del procedimiento administrativo.

b) Conducta de ministros y abogados integrantes. Tanto los ministros como los abogados integrantes han mantenido esa misma línea.

\section{Gráficos}

Véase Gráficos 1.1 y 1.2, más adelante.

2. Plazos fatales para que la Administración responda solicitudes del ciudadano. Las demoras o dilaciones de la Administración

Escenario jurisprudencial anterior (2008-2018)

$1^{\circ}$. Los ministros Brito y S. Muñoz sostienen la postura minoritaria que aboga por el cumplimiento de los plazos por parte de la Administración y reconocen que sí existen los plazos fatales. Es un criterio garantista y minoritario.

$2^{\circ}$. La Tercera Sala sostiene en la mayoría de los casos que el plazo del artículo 27 de la LBPA no es fatal. Pero, cuando las demoras exceden el plazo de 2 años, se inclina por una postura intermedia, llamada del "decaimiento". Si no se cumplen los requisitos para el decaimiento se inclina por la postura que sostiene que no hay plazos fatales para la Administración.

\section{Escenario jurisprudencial 2019}

a) Conducta de la sala. La Tercera Sala de la Corte Suprema ha mantenido un criterio uniforme durante 2019, en cuanto a que el plazo del artículo 27 de la LBPA no es fatal. Sin embargo, dentro de ese criterio distinguimos dos posturas, ya que en Almonacid (2019) falló que los plazos no son fatales para la Administración, mientras que en Clínica Alemana (2019) optó por la postura intermedia, resolviendo que lo que aplica es el decaimiento del acto administrativo. En Reveco (2019) la CS opta ipor los dos criterios!, esto es, afirma que los plazos son fatales y, a la vez, señala que solo si la demora excede los dos años se trataría de una antijuridicidad (¿?). 
b) Conducta de ministros y abogados integrantes. Se ha mantenido un criterio en apariencia único, consistente en que los plazos no son fatales para la Administración, sin perjuicio de que desde Clínica Alemana (2019) adoptan la postura intermedia, resolviendo que lo que aplica en la especie es el decaimiento del acto administrativo (a pesar de que renglones antes, esos mismos ministros afirman que los plazos no son fatales, pero en este caso sería una fatalidad de dos años).

Sin embargo, si comparamos el comportamiento de los ministros y abogados integrantes durante este año con el período anterior (2008-2018), podemos observar lo siguiente: el ministro Aránguiz en algunos casos elige el criterio 1 y en otros el criterio 2 del gráfico. En efecto, desde Muebles Issaurat (2017) ha sostenido uniformemente que el plazo del artículo 27 de la LBPA no es fatal, inclinándose en algunos casos por la postura 1 del gráfico, pero en otros como Clínica Alemana (2019) se inclina por la postura 2, del decaimiento (estos es, el plazo sería fatal a los dos años).

El ministro S. Muñoz, por su parte, en los años 2010, 2011 y 2012 votó por la postura 2 (del decaimiento), luego en 2013 votó por la postura 3, en seguida en 2017 votó una vez por la postura 2, para luego mantenerse hasta 2018 en la postura 3 (o sea, hizo una variación en 2013 y un zigzag en 2017); ahora, se mantiene en la postura 3, en un desarrollado voto, en Reveco (2019). Esto es, este ministro, en ocho ocasiones ha fallado por la postura 2 y en trece ocasiones lo ha hecho por la postura 3, siendo esta última su actual posición, al parecer. Las ministras Sandoval y Vivanco cambian su posición desde la postura 1 a la 2 durante 2019; durante los años anteriores la ministra Sandoval visitó ambas posturas; y la ministra Vivanco había votado por la primera postura. En apariencia, ambas posturas (1 y 2) reflejan para esos ministros un mismo criterio, consistente en que el plazo de seis meses del artículo 27 de la LBPA no es fatal; pero, como se dice más arriba, la postura 2 termina incorporando un criterio de fatalidad, pero de un plazo mayor: de dos años; lo que es una incoherencia con el predicamento general de que los plazos no serían fatales.

De ahí que se consignan tres posturas en los gráficos.

Gráficos

Véase Gráficos 2.1 y 2.2, más adelante.

3. Audiencia previa como requisito esencial del procedimiento administrativo de invalidación

Escenario jurisprudencial anterior (2008-2018)

Existe una línea jurisprudencial uniforme tanto de la corte como de ministros y abogados integrantes.

Escenario jurisprudencial 2019

ReDAE Revista de Derecho Administrativo Económico, Nº 31 [enero-junio 2020] pp. 251-299 
Tanto la Sala Tercera de la Corte Suprema como sus ministros y abogados integrantes han mantenido durante 2019 la uniformidad del periodo anterior, reconociendo la esencialidad de la audiencia previa del interesado en el procedimiento administrativo de invalidación.

Gráficos

Véase Gráficos 3.1 y 3.2, más adelante.

\section{Plazo de la administración para ejercer potestad sancionatoria}

Escenario jurisprudencial anterior (2008-2018)

a) Conducta de la Tercera Sala. La jurisprudencia de la Corte Suprema mostró zigzagueos, cambiando de tendencia en la medida que fue cambiando la integración de la sala. No obstante lo anterior, desde el caso Albala (2015) se ha mantenido uniforme, la que se ve interrumpida únicamente por el caso Fisco con Industrial (2015), el cual fue fallado por la Primera Sala.

b) Conducta de ministros y abogados integrantes

i. Línea que aplica las normas del CC. Se mantienen estables los ministros Pierry, Egnem y Aránguiz.

ii. Línea que aplica las normas del CP. Se mantienen dentro de la tendencia Carreño y S. Muñoz, quien cambia de tendencia en el último fallo recopilado. Cambia de parecer la ministra Sandoval, quien en un primer momento abrazó la tesis que aplica el CP, y luego abraza la tendencia que aplica luego las normas del CC, pero sin zigzagueo.

\section{Escenario jurisprudencial 2019}

a) Conducta de la sala. Durante el año 2019, la Corte Suprema mantuvo un criterio uniforme, consistente en aplicar el plazo de cinco años contemplado en el Código Civil, como plazo de la Administración para ejercer la potestad sancionatoria.

b) Conducta de ministros y abogados integrantes.

i. La línea que plantea la aplicación de las normas del Código Civil -particularmente el artículo 2595-, es seguida durante 2019 por los ministros Aránguiz, Sandoval, Vivanco y S. Muñoz.

ii. Votan por la aplicación de las normas del Código Penal, el abogado integrante Pallavicini, y el ministro Lagos.

iii. El ministro Prado cambia su voto: en una ocasión vota por una tendencia, y en otra ocasión vota por la contraria. Si se considera también el comportamiento de ministros y abogados integrantes durante el período 2008-2018, el ministro Prado incurre en dos zigzagueos, ya que en Laboratorios Lafi A (2018) estuvo por la aplicación de las normas del Código Penal, y durante 2019 votó por ambas posturas, siendo el último de estos pronun- 
ciamientos en Laboratorios Pharma Investi (2019), a favor de la aplicación del Código Civil.

Gráficos

Véase Gráficos 4.1 y 4.2, más adelante.

5. Agotamiento de la vía administrativa e interrupción del plazo para ejercer posteriores recursos jurisdiccionales

Escenario jurisprudencial anterior (2008-2018)

La Corte Suprema fue muy consistente y aplicó la regla del 54 inc. $2^{\circ}$ de la LBPA respetando el derecho del administrado al íntegro cómputo del plazo para accionar ante tribunales, salvo dos excepciones: Amodeo con Compin (2009) y Mansilla con Compin (2010). En ambos casos con votos disidentes del Ministro Brito, quien estuvo por aplicar la regla del artículo 54 inc. $2^{\circ}$. Hubo cambio de votos de los ministros Pierry y Carreño y del abogado integrante Gorziglia.

Escenario jurisprudencial 2019

Tanto la Tercera Sala de la Corte Suprema como sus ministros y abogados integrantes han sido consistente durante 2019 respecto al reconocimiento del derecho a interrupción del plazo para ejercer recursos jurisdiccionales, contemplado en el artículo 54, inciso $2^{\circ}$ de la LBPA.

\section{Gráficos}

Véase Gráficos 5.1 y 5.2, más adelante.

II. Conflictos al presentar recursos jurisdiccionales

\section{Plazo de prescripción de la acción de nulidad administrativa}

Escenario jurisprudencial anterior (2008-2018)

La Corte ofreció una línea uniforme, siguiendo la tesis mayoritaria, aplicando las normas del CC respecto de los efectos patrimoniales de la acción. Zigzaguean el ministro Prado y los abogados integrantes Matus y Quintanilla. El ministro S. Muñoz se mantiene de manera uniforme en la postura minoritaria que sostiene la imprescriptibilidad de la acción de nulidad.

\section{Escenario jurisprudencial 2019}

a) Conducta de la sala. La jurisprudencia de la Tercera Sala ha sido uniforme durante 2019, siguiendo la misma línea que sostuvo durante el período anterior, decidiendo la aplicación de las normas de prescripción del Código Civil.

b) Conducta de ministros y abogados integrantes. En este asunto, no hay cambio de votos por parte de quienes constituyen la sala, manteniendo 
una tendencia uniforme durante este período. Al comparar la situación del año 2019 con la del período 2008-2018, se puede extraer que el ministro Prado mantuvo el criterio que sostuvo en Corporación (2018), dejando de lado el zigzagueo en que incurrió anteriormente. Por su parte, el ministro S. Muñoz se mantiene uniforme en la postura disidente, sosteniendo que tanto la acción de nulidad de derecho público como sus efectos patrimoniales son imprescriptibles.

\section{Gráficos}

Véase Gráficos 6.1 y 6.2, más adelante.

\section{Cómputo del plazo para presentar recursos jurisdiccionales contra actos administrativos}

\section{Escenario jurisprudencial anterior (2008-2018)}

La jurisprudencia de la Corte Suprema falló de manera zigzagueante, pero aplicando mayoritariamente la LBPA. Después del caso Agrícola (2012) se deja por completo la línea que aplicaba el Código Civil, y la Corte se divide entre dos posturas: la de aplicar la LBPA o el CPC. La ministra Egnem y el abogado integrante Lagos, a partir del 2015 cambian desde la postura que aplicaba el Código Civil para adoptar la del CPC; pero una vez variada su posición se mantienen firmes en esa postura; esto es, no zigzaguean. Los ministros S. Muñoz, Pierry, Sandoval y el abogado integrante Rodríguez se mantienen firmes a partir del año 2013 en la postura que aplica la LBPA. Zigzaguean principalmente los ministros Aránguiz y Prado. La abogada integrante Etcheberry vota de acuerdo al CPC en la Cuarta Sala, pero cambia su voto en un caso posterior en la Tercera Sala.

\section{Escenario jurisprudencial 2019}

a) Conducta de la sala. La jurisprudencia de la Tercera Sala ha sido uniforme durante 2019 en cuanto a la aplicación del artículo 25 de la LBPA respecto al cómputo del plazo para presentar recursos jurisdiccionales contra actos administrativos, con lo cual abandona el constante zigzagueo mantenido durante el periodo 2008-2018.

b) Conducta de ministros y abogados integrantes. Los ministros y abogados integrantes también han mantenido una única opinión durante el 2019, aplicando el mencionado artículo 25 de la LBPA. De lo anterior, podemos inferir que ministros que anteriormente zigzaguearon, como Aránguiz y Prado, han uniformado su criterio, dejando de lado las vacilaciones. La ministra Chevesich, por su parte, en Miranda (2019) estuvo por la aplicación del artículo 66 del Código de Procedimiento Civil. No obstante, si comparamos con el período anterior, podemos concluir que mantiene un criterio lineal, ya que votó de la misma forma en Albasini (2017) y Transportes (2017). 
Gráficos

Véase Gráficos 7.1 y 7.2, más adelante.

8. Prescripción de la acción indemnizatoria de responsabilidad patrimonial de la Administración

Escenario jurisprudencial anterior (2008-2018)

Entre 2008 y 2018, la Corte Suprema falló de manera uniforme según el criterio que promueve la aplicación de las normas del Código Civil a casos en que se presentan acciones indemnizatorias por responsabilidad patrimonial de la Administración. No obstante, el ministro S. Muñoz mantiene constante y uniformemente su voto minoritario.

\section{Escenario jurisprudencial 2019}

a) Conducta de la sala. La Tercera Sala de la Corte Suprema ha mantenido de manera consistente el criterio sostenido uniformemente durante el período anterior, en que la acción indemnizatoria por falta de servicio, seguida contra de los órganos administrativos, prescribe de acuerdo al plazo señalado en el artículo 2332 del Código Civil.

b) Conducta de ministros y abogados integrantes. Ministros y abogados integrantes votaron de manera uniforme durante 2019, siguiendo la tendencia del período 2008-2018. El ministro S. Muñoz mantiene su postura disidente en este aspecto, planteando que las normas contenidas en el Código Civil relativas a la prescripción no son aplicables en materia de acciones indemnizatorias por responsabilidad del Estado, fundándose principalmente en que los principios inspiradores del Derecho Público no son compatibles con aquellos que se encuentran en el Derecho Privado.

\section{Gráficos}

Véase Gráficos 8.1 y 8.2, más adelante.

9. Prescripción de la acción indemnizatoria por crímenes de lesa humanidad por agentes del Estado

Escenario jurisprudencial anterior (2008-2018)

a) Conducta de la Corte Suprema. La jurisprudencia cambiaba según la sala de la Corte Suprema que conoció las causas. En un primer período (desde 2008 hasta mediados del 2013), en los casos los conoció la Tercera Sala hubo una tendencia marcada por la aplicación de las normas del CC. En un segundo período (desde fines del 2013 hasta 2018), comienza a conocer estos casos la Segunda Sala, con lo que se asienta la tendencia contraria, esto es, la imprescriptibilidad de la acción, la que fue estable desde el año 2014. 
b) Conducta de ministros y abogados integrantes. En este asunto, no hubo cambios de votos por parte de quienes integran las salas respectivas, manteniendo sus votos.

i. Línea que considera prescriptible la acción. Los ministros de la Tercera Sala Carreño, Pierry, Sandoval y Prado se mantienen en esta tendencia, sin zigzagueos.

ii. Línea que considera imprescriptible la acción. En esta línea se encuentran los ministros de la Segunda Sala Dolmestch, Künsemüller, Brito y S. Muñoz, todos con votaciones uniformes.

\section{Escenario jurisprudencial 2019}

Tanto la Segunda Sala de la Corte Suprema como sus ministros y abogados integrantes, la que ha conocido todos los casos, ha mantenido un criterio uniforme durante 2019, sosteniendo la imprescriptibilidad de la acción indemnizatoria por crímenes de lesa humanidad por agentes del Estado. Con esto, ratifica la postura que ha seguido desde 2015.

Gráficos

Véase Gráficos 9.1 y 9.2, más adelante.

\section{Legitimación activa para ejercer la acción de protección}

La Corte Suprema no conoció casos relativos a esta materia durante el año 2019.

\section{Procedencia y alcance de la acción de mera certeza}

La Corte Suprema no conoció casos relativos a esta materia durante el año 2019.

III. Conflictos relativos a la estabilidad de los trabajadores en la administración

\section{Funcionarios a honorarios y supletoriedad del Código del Trabajo}

\section{Escenario jurisprudencial anterior (2008-2018)}

a) Conducta de la Cuarta Sala. La jurisprudencia fue zigzagueante en esta materia, mostrando uniformidad solo en un primer período.

b) Conducta de los ministros y abogados integrantes. Los ministros y abogados integrantes no mantienen su voto durante el período estudiado, salvo algunas excepciones, como la ministra Chevesich, quien siempre aboga por la aplicación de las normas del CT a las relaciones surgidas en virtud de un contrato a honorarios. Zigzaguean los ministros Blanco y A. Muñoz y la abogada integrante Etcheberry.

Escenario jurisprudencial 2019 
a) Conducta de la Cuarta Sala: Podemos distinguir dos períodos:

i) Primer semestre: continúa el zigzagueo. Durante un primer período (hasta mayo) la Cuarta Sala continuó con los zigzagueos jurisprudenciales, resolviendo en dos sentidos. Una tendencia dictaminó que no debía aplicarse la normativa contenida en el Código del Trabajo a las relaciones existentes entre la Administración del Estado y una persona natural en virtud de un contrato a honorarios. La otra tendencia resolvió que debía hacerse un análisis de la naturaleza de la mentada relación; en algunos casos se configuró una relación laboral y por ende, se puede aplicar el Código del Trabajo y en los demás, el vínculo se rige por las normas del Estatuto Administrativo.

ii) Segundo semestre: ¡La Cuarta Sala dejó de zigzaguear! No obstante lo anterior, a partir del caso Domíguez (2019), de junio, la jurisprudencia de la Sala se estabiliza completamente, resolviendo el mencionado caso y los sucesivos sin darle aplicación al Código del Trabajo. En contraste con lo ocurrido durante el periodo 2008-2018, podemos ver entonces en el año 2019 una tendencia que apunta hacia la uniformidad jurisprudencial. Sin embargo, solo en el futuro sabremos si esta actual uniformidad se encuentra del todo consolidada.

b) Conducta de ministros y abogados integrantes: En relación a este aspecto, debemos distinguir dos momentos.

i) Algunos ministros siguen zigzagueando. El primer período (hasta mayo) se distingue por los votos zigzagueantes realizados por la mayoría de los integrantes de la Sala, con excepción de la Ministra Chevesich, quien se mantiene uniforme en su votación.

ii) ¡Ahora todos los ministros dejan de zigzaguear! El segundo período (desde junio), que se inicia con el caso Domínguez (2019), de junio, muestra estabilidad en los votos de aquellos que antes habían zigzagueado, manteniéndose, nuevamente, la Ministra Chevesich estable en su votación contraria a la mayoría. En relación a los fallos dictados entre los años 2008-2018, podemos ver que la conducta de los integrantes de la Sala no sufrió variación alguna hasta la resolución del mencionado caso Domínguez (2019). Con ese fallo, el Ministro Blanco y la Ministra A. Muñoz comienzan a votar en un solo sentido, manteniéndose uniformes hasta el final del período estudiado.

Gráficos

Véase Gráficos 12.1 y 12.2, más adelante.

\section{Término anticipado de empleos a contrata}

Escenario jurisprudencial anterior (2008-2018)

a) Conducta de la Tercera Sala. En esta materia, la Tercera Sala de la Corte Suprema zigzagueó constantemente. 
b) Conducta de los ministros y abogados integrantes. Los ministros y abogados integrantes cambiaron continuamente su voto, salvo algunas excepciones, como la ministra Egnem quien, en general se mantiene dentro de una tendencia, zigzagueando solo en contadas oportunidades. Es el mismo caso de los ministros S. Muñoz y Carreño.

\section{Escenario jurisprudencial 2019}

a) Conducta de la Tercera Sala. Continúan los zigzagueos por parte de la Sala en esta materia. Se pueden distinguir tres períodos: el primero, zigzagueante por parte de la Sala; un segundo período que inicia con el caso De la Fuente (2019), de mayo, en el que se muestra una clara tendencia a no aceptar la precariedad de los empleos a contrata existentes en la Administración del Estado; y, por último, al finalizar el año, una nueva serie de zigzagueos, resolviendo la Tercera Sala en un sentido y en otro indistintamente. Entonces, en relación a los fallos del período 2008-2018, no se ve por parte de la Sala la consolidación de una tendencia jurisprudencial, esto, principalmente, por el constante cambio de integración de la Sala y por los ya mencionados zigzagueos de sus ministros.

b) Conducta de ministros y abogados integrantes. Durante el 2019, la mayoría de los ministros y abogados integrantes de la Sala zigzaguean constantemente, mostrando sin embargo en algunos períodos cierta estabilidad en su votación; en algunos casos podemos ver que votan de acuerdo a una tendencia, luego, resuelven conforme a la tendencia contraria y por último, fallan nuevamente de acuerdo a la primera tendencia; esto, en sucesivas ocasiones durante el período estudiado. Muestra de ello son los votos zigzagueantes de los ministros Prado, Aránguiz y Vivanco. La excepción a este comportamiento es la votación del ministro S. Muñoz, quien vota de manera uniforme, acogiendo la tendencia de no aceptar la precariedad del empleo a contrata. Mantiene también estable su votación el abogado integrante Pallavicini quien, al contrario, acepta la precariedad de los mencionados empleos. En comparación con lo ocurrido en el período 2008-2018 no hay grandes variaciones en las conductas de los ministros y abogados integrantes de la Tercera Sala, manteniéndose uniforme solo la votación del ministro S. Muñoz.

\section{Gráficos}

Véase Gráficos 13.1 y 13.2, más adelante.

\section{Desviación de poder en las desvinculaciones de los funcionarios a contrata}

Escenario jurisprudencial anterior (2008-2018)

a) Comportamiento de la Tercera Sala. Es posible distinguir dos períodos:

i. Período 2011 a 2014. La Corte mantuvo un único criterio, identificando y reconociendo el vicio de desviación de poder. 
ii. Período de 2014 a 2018. Aquí se observó no solo un constante zigzagueo sino también una usual discrepancia de criterios en la resolución de los distintos casos. Una notoria dispersión de criterios de resolución. De hecho, está tan fracturada o dividida la sala que en todas las sentencias hay votos disidentes en uno $u$ otro sentido.

b) Comportamiento de ministros y abogados integrantes.

i. La línea que reconoce el vicio de desviación de poder en estos casos ha sido seguida por los ministros Pierry, Sandoval y Carreño (los que, sin embargo, cambian constantemente sus votos) y S. Muñoz (quien se mantiene constantemente en la línea que él sigue, sin cambiar nunca su voto).

ii. La segunda línea, que desconoce la ilegalidad, ha sido seguida por los ministros Egnem, Sandoval y Prado, los que, sin embargo, vacilan constantemente, salvo el abogado integrante Matus quien en esta ocasión se mantiene en una sola línea.

\section{Escenario jurisprudencial 2019}

a) Conducta de la Tercera Sala. Durante el año 2019 mantiene el zigzagueo respecto al reconocimiento o desconocimiento de la desviación de poder como vicio de legalidad en la desvinculación de funcionarios a contrata. Sin embargo, a contar del mes de mayo, en Ganga (2019), mantuvo una postura uniforme, en cuanto al reconocimiento de la desviación de poder en tales desvinculaciones.

b) Conducta de ministros y abogados integrantes. Existen dos líneas:

i) La línea que reconoce el vicio de desviación de poder ha sido seguida por los ministros Vivanco, Aránguiz y Prado (los que, sin embargo, han incurrido en zigzagueos durante el año 2019, situación que se viene arrastrando desde el período anterior en el caso de Aránguiz y Prado). El ministro S. Muñoz también sigue esta postura, pero de manera uniforme, sin cambiar de voto.

ii) La segunda línea, que desconoce la desviación de poder en la desvinculación de funcionarios a contrata, ha sido seguida durante 2019 por la ministra Sandoval, sin embargo, ésta vuelve a incurrir en zigzagueos.

Gráficos

Véase Gráficos 14.1 y 14.2, más adelante.

15. Recurso de protección como vía idónea en casos de desvinculación de funcionarios a contrata

Escenario jurisprudencial anterior (2008-2018)

a) Comportamiento de la sala. La jurisprudencia de la Tercera Sala zigzagueó constantemente. 
b) Comportamiento de ministros y abogados integrantes. Votaron por acoger los recursos de protección, inclinándose por la garantía de la igualdad, los ministros Brito, S. Muñoz y Pierry (sin perjuicio que este último cambia su voto constantemente). El ministro Cerda se inclina, exclusivamente, por la garantía de la propiedad. La línea que rechaza los recursos de protección, es seguida por los ministros Pierry, Sandoval, Egnem, Aránguiz y Prado, y el abogado integrante Quintanilla. Sin perjuicio todos ellos cambian de voto constantemente.

\section{Escenario jurisprudencial 2019}

a) Conducta de la sala. La Tercera Sala mantiene durante los primeros meses del año el zigzagueo constante del período anterior. Sin embargo, a partir del mes de junio, específicamente en Barahona (2019), unificó su criterio en pos de aceptar el recurso de protección como vía idónea en casos de desvinculación de funcionarios a contrata, fundándose para ello, principalmente, en una vulneración a la garantía de la igualdad ante la ley. La estabilidad en los fallos de la mencionada sala se mantiene durante algunos meses, volviendo a su conducta zigzagueante con el caso Pavez (2019), dando cuenta, hasta el término del año, de múltiples resoluciones en uno y otro sentido. En relación a la conducta mostrada por la Sala durante el período 2008-2018 no hay mayores cambios, dada la continuidad del zigzagueo, la cual solo se ve interrumpida por ciertos fallos sucesivos que se resuelven en un mismo sentido.

b) Conducta de ministros y abogados integrantes. Los ministros y abogados integrantes de la Tercera Sala zigzaguean constantemente durante el 2019, admitiendo y rechazando al recurso de protección como vía idónea en casos de desvinculaciones de funcionarios a contrata. Sin embargo, encontramos posturas uniformes, como la del ministro $S$. Muñoz, quien se mantiene absolutamente estable en sus votos, aceptando el recurso de protección como vía idónea respecto a casos de desvinculación de funcionarios a contrata. Contrario al comportamiento descrito anteriormente, zigzagueando constantemente, son los ministros Prado, Vivanco, Sandoval y el abogado integrante Pallavicini; este último, al final del período analizado muestra una votación uniforme.

Durante el período 2008-2018, los integrantes de la Tercera Sala, en su mayoría, zigzaguearon constantemente. En virtud de lo señalado anteriormente, no existe cambio en el comportamiento tanto de ministros como de abogados integrantes en esta materia.

\section{Gráficos}

Véase Gráficos 15.1 y 15.2, más adelante.

IV. Conflictos en recursos naturales, medio ambiente y bienes públicos

16. Regularización de derechos de aguas 
Escenario jurisprudencial anterior (2008-2018)

Hasta 2014, la tendencia uniforme fue aceptar las solicitudes de regularización de derechos de aguas por la unanimidad de la sala. Pero ese año la situación cambió, comenzando a mostrarse una tendencia a rechazar estas solicitudes. Sin embargo, este cambio no fue total ni uniforme. La Sala fue extremadamente vacilante en esta materia. La nueva tendencia, sustentada principalmente a partir de los votos de los ministros Pierry, Sandoval y Aránguiz (estos dos últimos, no obstante, suelen zigzaguear), se enfrentó continuamente a votos disidentes de ministros que siguen el criterio anterior (Egnem y S. Muñoz, los que mantienen de modo uniforme la línea que acepta las regularizaciones). Es posible igualmente identificar: i) aquellos ministros y abogados integrantes que solo variaron su tendencia de una a otra (ministros Brito, Ballesteros, y abogados integrantes Bates y Rodríguez); ii) como aquellos ministros que zigzaguean y cambian constantemente sus votos, adhiriendo a una u otra tendencia (son los ministros, Prado, Sandoval y Aránguiz y abogados integrantes Lagos, Quintanilla y Matus).

\section{Escenario jurisprudencial 2019}

a) Conducta de la sala. Durante el año 2019, la Tercera Sala mantuvo el vacilante comportamiento del período 2008-2018, en que zigzagueó constantemente. Inició el año rechazando la procedencia de la regularización en dos casos, para posteriormente, en Moreno (2019) y Lay Son (2019), cambiar de criterio y acceder a la misma.

b) Conducta de ministros y abogados integrantes. Votan aceptando la regularización de derechos de aprovechamiento de aguas los ministros Blanco, S. Muñoz, Vivanco y Biel (estos dos últimos, sin embargo, también votaron rechazando la regularización durante 2019). Rechazan la regularización de derechos de aprovechamiento durante el año 2019 la ministra Sandoval y los abogados integrantes Pallavicini y Gajardo. En el caso de la ministra Sandoval, vemos que ésta deja de lado los zigzagueos incurridos durante el período 2008-2018, para uniformar su postura en orden a rechazar la procedencia de la regularización de derechos de aguas. El ahora abogado integrante Pierry mantuvo su voto tradicional en la materia rechazando la regularización.

Gráficos

Véase Gráficos 16.1 y 16.2, más adelante.

\section{Autorizaciones administrativas como requisito de servidumbres mineras}

La Corte Suprema no conoció casos relativos a esta materia durante el año 2019.

\section{Plazo para que tercero absoluto pueda solicitar invalidación ambiental}

Escenario jurisprudencial período 2008-2018

ReDAE Revista de Derecho Administrativo Económico, Nº 31 [enero-junio 2020] pp. 251-299 
a) Comportamiento de la Tercera Sala. Ha existido un constante zigzagueo en la jurisprudencia de la Tercera Sala de la Corte Suprema.

b) Conducta de ministros y abogados integrantes. La línea jurisprudencial que aplica el plazo de dos años fue seguida, sin cambio de votos, por los ministros Egnem, S. Muñoz y Valderrama. La línea jurisprudencial que aplica el plazo de treinta días, y que fuera creada en un voto de prevención del ministro Pierry, fue seguida constantemente por este último y la ministra Sandoval. Los ministros Carreño, Aránguiz y Prado cambian de voto entre una y otra línea jurisprudencial.

\section{Escenario jurisprudencial 2019}

Durante el año 2019, la Corte Suprema solo se pronunció en una oportunidad sobre el plazo para que un tercero absoluto pueda solicitar la invalidación ambiental. Esto sucedió en Comunidad Agrícola La Dormida (2019), caso en que la Sala declara la inadmisibilidad, pero lo que resulta es la contradicción con un caso anterior en cuanto al fondo, y ahora resulta que el plazo larvado para solicitar una invalidación que resulta (al quedar a firme la sentencia de la Corte de Apelaciones) es de dos años. ¿Una forma larvada de zigzaguear?

\section{Gráficos}

Véase Gráficos 18.1 y 18.2, más adelante.

\section{Afectación presunta de bienes privados al uso público}

La Corte Suprema no conoció casos sobre esta materia durante el año 2019.

20. Acceso a playas públicas

La Corte Suprema no conoció casos sobre esta materia durante el año 2019. 
Gráfico 1.1. Comportamiento de la Sala: Cómputo de plazos durante la tramitación del procedimiento administrativo

\begin{tabular}{|c|c|c|}
\hline AÑo & $\begin{array}{c}\text { CASOS QUE APLICAN CORRECTAMENTE ART. } 25 \\
\text { LBPA }\end{array}$ & $\begin{array}{c}\text { CASOS QUE NO APLICAN CORRECTAMENTE } \\
\text { REGLA ART. } 25 \text { LBPA }\end{array}$ \\
\hline \multirow[t]{7}{*}{2019} & FRIGORÍFICO KARMAC SPA & \\
\hline & EATON & \\
\hline & EMBOTELLADORA & \\
\hline & DISTRIBUIDORA VERGIO S.A. & \\
\hline & CHILEVISIÓN S.A. & \\
\hline & RED UC ChRISTUS & \\
\hline & SANZONE & \\
\hline & & (C) PDAE UC 20 \\
\hline
\end{tabular}

Gráfico 1.2. Comportamiento de ministros y abogados integrantes: Cómputo de plazos durante la tramitación del procedimiento administrativo

\begin{tabular}{|c|c|c|c|}
\hline AÑo & CASO & CASOS QUE APLICAN CORRECTAMENTE ART. 25 LBPA & $\begin{array}{c}\text { CASOS QUE NO APLICAN CORRECTAMENTE REGLA ART. } \\
25 \text { LBPA }\end{array}$ \\
\hline \multirow[t]{7}{*}{2019} & FRIGORÍFICO KARMAC SPA & [S. Myñoz][Prado][Vivanco][Etcheberry][Gómez] & \\
\hline & EATON & [S. Muñoz][Sandoval][Vivanco][Matus][Barra] & \\
\hline & EMBOTELLADORA & [Aránguiz][Sandoval][Vivanco][Munita] $\quad$ [Pierry] & \\
\hline & DISTRIBUIDORA VERGIO S.A. & [S. Muñoz][Sandoval][Vivanco][Pallavicini][Pierry] & \\
\hline & CHILEVISIÓN S.A. & [S. Muñoz][Sandoval][Vivanco][Aránguiz][Prado] & \\
\hline & RED UC CHRISTUS & [S. Muñoz][Sandoval][Quintanilla][Aránguiz][Pierry] & \\
\hline & SANZONE & [S. MV n̊oz][Sanḑoval][Vivanco][Arángülz][Quintanilla] & \\
\hline
\end{tabular}

Gráfico 2.1. Comportamiento de la sala: Plazos fatales para que la Administración responda solicitudes del ciudadano. Las demoras o dilaciones de la Administración

\begin{tabular}{|c|c|c|c|}
\hline \multirow[b]{2}{*}{ Año } & \multicolumn{2}{|c|}{ ARTÍCULO 27 LBPA NO ES FATAL } & \multirow[b]{2}{*}{$\begin{array}{l}\text { POSTURA PRO CUMPLIMIENTO DE } \\
\text { PLAZOS POR LA ADMINISTRACIÓN }\end{array}$} \\
\hline & $\begin{array}{c}\text { SOSTIENEN INEXISTENCIA DE PLAZOS } \\
\text { FATALES }\end{array}$ & POSTURA DEL DECAIMIENTO & \\
\hline \multirow[t]{3}{*}{2019} & ALMONACID & & \\
\hline & & CLÍNICA ALEMANA & \\
\hline & REVECO & REVECO & \\
\hline
\end{tabular}

Gráfico 2.2. Conducta de los ministros: Plazos fatales para que la Administración responda solicitudes del ciudadano. Las demoras o dilaciones de la Administración

\begin{tabular}{|c|c|c|c|c|}
\hline \multirow{2}{*}{ AÑo } & \multirow{2}{*}{ CASO } & \multicolumn{2}{|c|}{ ARTícULO 27 LBPA NO ES FATAL } & POSTURA PRO CUMPLIMIENTO DE PLAZOS POR LA \\
ADMINISTRACIÓN
\end{tabular}

Gráfico 3.1. Comportamiento de la sala: Audiencia previa como requisito esencial del procedimiento administrativo de invalidación

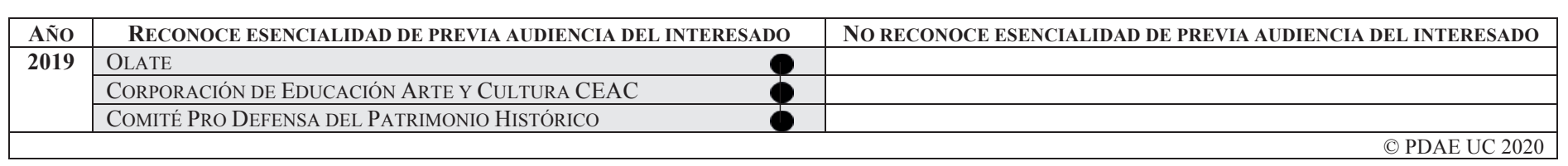

Gráfico 3.2. Comportamiento de los ministros: Audiencia previa como requisito esencial del procedimiento administrativo de invalidación

\begin{tabular}{|c|c|c|c|}
\hline AÑ̃ & CASO & $\begin{array}{l}\text { RECONOCE ESENCIALIDAD DE PREVIA AUDIENCIA DEL } \\
\text { INTERESADO }\end{array}$ & $\begin{array}{l}\text { NO RECONOCE ESENCIALIDAD DE PREVIA AUDIENCIA DEL } \\
\text { INTERESADO }\end{array}$ \\
\hline \multirow[t]{3}{*}{2019} & Olate & [Sarl doval] [V vanco] [S. Muñoz] [Munita] [Prado] & \\
\hline & $\begin{array}{l}\text { CORPORACIÓN DE EDUCACIÓN } \\
\text { ARTE Y CULTURA CEAC }\end{array}$ & [Sar doval] [V vanco][S. & \\
\hline & $\begin{array}{l}\text { COMITÉ PRo DEFENSA DEL } \\
\text { PATRIMONIO HISTÓRICO }\end{array}$ & $\sqrt[[\text { Sar doval] }[\mathrm{V} \text { vanco][S }]{\curlyvee \text { uñoz][Ar }}$ & \\
\hline
\end{tabular}

Gráfico 4.1. Comportamiento de la sala: Plazo de la Administración para ejercer potestad sancionatoria

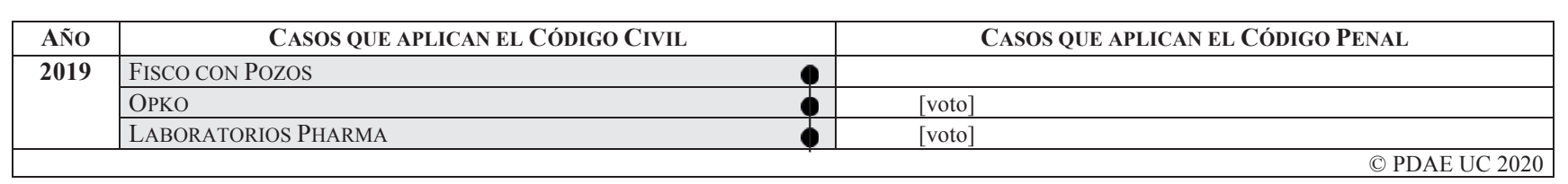


Gráfico 4.2. Comportamiento de ministros y abogados integrantes: Plazo de la Administración para ejercer potestad sancionatoria

\begin{tabular}{|c|c|c|c|c|c|}
\hline \multirow{4}{*}{$\frac{\text { ANO }}{2019}$} & CASO & \multicolumn{3}{|c|}{ CASOS QUE APLICAN EL CÓDIGO CIVIL } & \multirow[t]{2}{*}{ CASOS QUE APLICAN EL CÓDIGO PENAL } \\
\hline & FISCO CON POZOS & [Blanco] [Biel] [S. Muñoz] [J. Muñoz] & [Vivanco] & $\mathbf{p}$ & \\
\hline & OPKO & [Barra] [Arángguiz] [Quintanilla] & [Vivanco] & 6 & [Prado] \\
\hline & LABORATORIOS PHARMA INVESTI & [Prado] [Arànguiz] [S. Muñoz] [Sandove & Sáez] & 6 & [Lagos][Pallavicini] \\
\hline
\end{tabular}

Gráfico 5.1. Comportamiento de la sala: Agotamiento de la vía administrativa e interrupción del plazo para ejercer posteriores recursos jurisdiccionales

\begin{tabular}{|c|l|c|c|}
\hline \multirow{2}{*}{ AÑo } & \multicolumn{1}{|c|}{$\begin{array}{c}\text { RECONOCE EL DERECHO A INTERRUPCIÓN DEL ART. } 54 \text { INC. } 2^{\circ} \\
\text { LBPA }\end{array}$} & $\begin{array}{c}\text { NO RECONOCE EL DERECHO A INTERRUPCIÓN DEL ART. 54 INC. } 2^{\circ} \\
\text { LBPA }\end{array}$ \\
\hline \multirow{2}{*}{2019} & PINEDA & & \\
\cline { 2 - 4 } & LAGOS & & \\
\hline
\end{tabular}

Gráfico 5.2. Comportamiento de ministros y abogados integrantes: Agotamiento de la vía administrativa e interrupción del plazo para ejercer posteriores recursos jurisdiccionales

\begin{tabular}{|c|c|c|c|}
\hline AÑo & CASO & $\begin{array}{l}\text { RECONOCE EL DERECHO A INTERRUPCIÓN DEL ART. } 54 \\
\text { INC. } 2^{\circ} \text { LBPA }\end{array}$ & $\begin{array}{l}\text { NO RECONOCE EL DERECHO A INTERRUPCIÓN DEL ART. } 54 \\
\text { INC. } 2^{\circ} \text { LBPA }\end{array}$ \\
\hline \multirow[t]{2}{*}{2019} & PINEDA & [S. Muñoz][Sandoval][Aránguiz][Prado][Vivanco] & \\
\hline & LAGOS & [S. Nâñoz][Sandôval][Arănguiz][Munita][Pierry] & \\
\hline
\end{tabular}

Gráfico 6.1. Comportamiento de la sala: Plazo de prescripción de la acción de nulidad administrativa

\begin{tabular}{|c|l|c|c|}
\hline \multirow{2}{*}{ AÑo } & $\begin{array}{l}\text { LA ACCIÓN DE NULIDAD ESTÁ SUJETA } \\
\text { A LAS REGLAS DE PRESCRIPCIÓN DEL } \\
\text { CC CUANDO TIENE UN COMPONENTE } \\
\text { PATRIMONIAL }\end{array}$ & $\begin{array}{c}\text { LA ACCIÓN DE NULIDAD Y LA ACCIÓN } \\
\text { PATRIMONIAL PRESCRIBEN SEGÚN } \\
\text { LAS REGLAS DEL CC }\end{array}$ & $\begin{array}{c}\text { TANTO LA ACCIÓN DE NULIDAD } \\
\text { COMO SUS EFECTOS PATRIMONIALES } \\
\text { SON IMPRESCRIPTIBLES }\end{array}$ \\
\hline \multirow{2}{*}{2019} & \multicolumn{1}{|l|}{ PESQUERA } & & OPDAE UC 2020 \\
\hline
\end{tabular}

Gráfico 6.2. Comportamiento de ministros y abogados integrantes: Plazo de prescripción de la acción de nulidad administrativa

\begin{tabular}{|c|c|c|c|r|}
\hline \multirow{2}{*}{ AÑo } & CASO & $\begin{array}{c}\text { LA ACCIÓN DE NULIDAD ESTÁ SUJETA A LAS } \\
\text { REGLAS DE PRESCRIPCIÓN DEL CC CUANDO } \\
\text { TIENE UN COMPONENTE PATRIMONIAL }\end{array}$ & $\begin{array}{c}\text { LA ACCIÓN DE NULIDAD Y LA ACCIÓN } \\
\text { PATRIMONIAL PRESCRIBEN SEGÚN LAS } \\
\text { REGLAS DEL CC }\end{array}$ & $\begin{array}{c}\text { TANTO LA ACCIÓN DE NULIDAD COMO SUS } \\
\text { EFECTOS PATRIMONIALES SON } \\
\text { IMPRESCRIPTIBLES }\end{array}$ \\
\hline \multirow{2}{*}{2019} & PESQUERA & {$[$ Sandoyal] [Prado] [Vivanco] [De la Maza] } & & [S. Mliñoz] \\
\cline { 2 - 5 } & COMUNIDAD & {$[$ [Sanq̧oval] [Aránguiz] [Vivanco] [Quintanilla] } & & [S. Mưnoz] \\
\hline
\end{tabular}

Gráfico 7.1 Comportamiento de la sala: Cómputo del plazo para presentar recursos jurisdiccionales contra actos administrativos

\begin{tabular}{|c|c|c|c|}
\hline Año & APLICAN ART. 25 LBPA & APLICAN ART. 66 CPC & APLICAN ART. 50 CC \\
\hline \multirow[t]{7}{*}{2019} & \begin{tabular}{|l|} 
MIRANDA \\
\end{tabular} & [voto] & \\
\hline & EGAÑA & & \\
\hline & DISTRIBUIDORA VERGIO & & \\
\hline & RED DE TELEVISIÓN CHILEVISIÓN & & \\
\hline & RED UC CHRISTUS & & \\
\hline & SANZONE & & \\
\hline & TELEVISIÓN NACIONAL DE CHILE & & \\
\hline
\end{tabular}

Gráfico 7.2. Comportamiento de ministros y abogados integrantes: Cómputo del plazo para presentar recursos jurisdiccionales contra actos administrativos

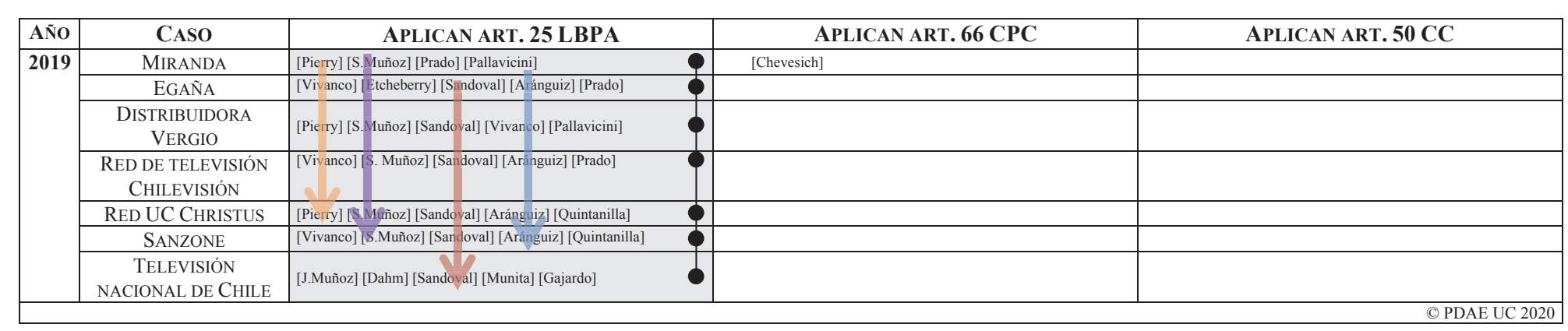

Gráfico 8.1. Comportamiento de la sala: Prescripción de la acción indemnizatoria de responsabilidad

\begin{tabular}{|c|c|c|}
\hline AÑ̃ & $\begin{array}{c}\text { LAS NORMAS DEL CÓDIGO CIVIL SOBRE } \\
\text { PRESCRIPCIÓN NO SON APLICABLES A LA } \\
\text { ACCIÓN INDEMNIZATORIA DE } \\
\text { RESPONSABILIDAD }\end{array}$ & $\begin{array}{c}\text { LAS NORMAS DEL CÓDIGO CIVIL SOBRE } \\
\text { PRESCRIPCIÓN SON APLICABLES A LA } \\
\text { ACCIÓN INDEMNIZATORIA DE } \\
\text { RESPONSABILIDAD }\end{array}$ \\
\hline \multirow[t]{6}{*}{2019} & [voto] & ALEGRÍA \\
\hline & [voto] & ALCAMINO \\
\hline & [voto] & LABORATORIOS \\
\hline & [voto] & OLATE \\
\hline & [voto] & BÁEZ \\
\hline & & (c) PDAE UC 2020 \\
\hline
\end{tabular}


Gráfico 8.2. Comportamiento ministros y abogados integrantes: Prescripción de la acción indemnizatoria de responsabilidad

\begin{tabular}{|c|c|l|r|}
\hline \multirow{4}{*}{ AÑo } & CASO & $\begin{array}{c}\text { LAS NORMAS DEL CÓDIGO CIVIL SOBRE } \\
\text { PRESCRIPCIÓN NO SON APLICABLES A LA ACCIÓN } \\
\text { INDEMNIZATORIA DE RESPONSABILIDAD }\end{array}$ & $\begin{array}{r}\text { LAS NORMAS DEL CÓDIGO CIVIL SOBRE } \\
\text { PRESCRIPCIÓN SON APLICABLES A LA ACCIÓN } \\
\text { INDEMNIZATORIA DE RESPONSABILIDAD }\end{array}$ \\
\hline \multirow{3}{*}{2019} & ALEGRÍA & {$[$ S. Muñoz] } & [Munita][Aránguiz][Abuauad][Sandoval] \\
\cline { 2 - 5 } & ALCAMINO & {$[$ S. Muñoz] } & [Vivanco][Prado][Matus][Sandoval] \\
\cline { 2 - 5 } & LABORATORIOS & {$[$ S. Muñoz] } & [Vivanco][Quintanilla][Pallavicini][Sandoval] \\
\cline { 2 - 5 } & OLATE & {$[$ S. Muñoz] } & [Vivanco][Prado][Pierry][Sandoval] \\
\cline { 2 - 5 } & BÁEZ & {$[$ S. Muñoz] } & [Vivancou[Aránguiz][Pallavicini][Sandoval] \\
\hline
\end{tabular}

Gráfico 9.1. Comportamiento de sala: Prescripción de la acción indemnizatoria de crímenes de lesa humanidad por agentes del Estado. [En cada caso se indica la sala que conoció el recurso]

\begin{tabular}{|c|c|c|}
\hline AÑ̃ & $\begin{array}{c}\text { ACCIÓN PRESCRIPTIBLE SEGÚN NORMAS DEL } \\
\text { CÓDIGO CIVIL (ART. 2.332) }\end{array}$ & $\begin{array}{l}\text { ACCIÓN IMPRESCRIPTIBLE POR APLICACIÓN DE } \\
\text { TRATADOS Y CONVENIOS INTERNACIONALES }\end{array}$ \\
\hline \multirow[t]{18}{*}{2019} & & BASTÍAS (2 ${ }^{\mathrm{a}} \mathrm{S}$. $)$ \\
\hline & & MORALES $\left(2^{\mathrm{a}} \mathrm{S}.\right)$ \\
\hline & & CAUCOTO I ( $\left.2^{\mathrm{a}} \mathrm{S}.\right)$ \\
\hline & & CAUCOTO II ( $\left(2^{\mathrm{a}} \mathrm{S}.\right)$ \\
\hline & & CORTÉS ( $\left.2^{\mathrm{a}} \mathrm{S}.\right)$ \\
\hline & & FERNÁNDEZ (2 $\left.{ }^{\mathrm{a}} \mathrm{S}.\right)$ \\
\hline & & GARCÍA (2 ${ }^{\mathrm{a}} \mathrm{S}$.) \\
\hline & & GONZÁLEZ $\left(2^{\mathrm{a}} \mathrm{S}\right.$.) \\
\hline & & POZO $\left(2^{a}\right.$ S. $)$ \\
\hline & & MUÑOZ (2 $\left.{ }^{\mathrm{a}} \mathrm{S}.\right)$ \\
\hline & & GONZÁLEZ (2 $\left.{ }^{\mathrm{a}} \mathrm{S}.\right)$ \\
\hline & & OSSES (2a S.) \\
\hline & & TORREALBA $\left(2^{\mathrm{a}} \mathrm{S}.\right)$ \\
\hline & & CÁRCAMO $\left(2^{\mathrm{a}} \mathrm{S}.\right)$ \\
\hline & & BAEZA ( $2^{\text {a }}$ S. $)$ \\
\hline & & FISCO $\left(2^{\mathrm{a}}\right.$ S. $)$ \\
\hline & & BRAVO (2a ${ }^{a}$ S. $)$ \\
\hline & & (C) PDAE UC 2020 \\
\hline
\end{tabular}

Gráfico 9.2. Conducta de los ministros y abogados integrantes: Prescripción de la acción indemnizatoria contra crímenes de lesa humanidad por agentes del Estado

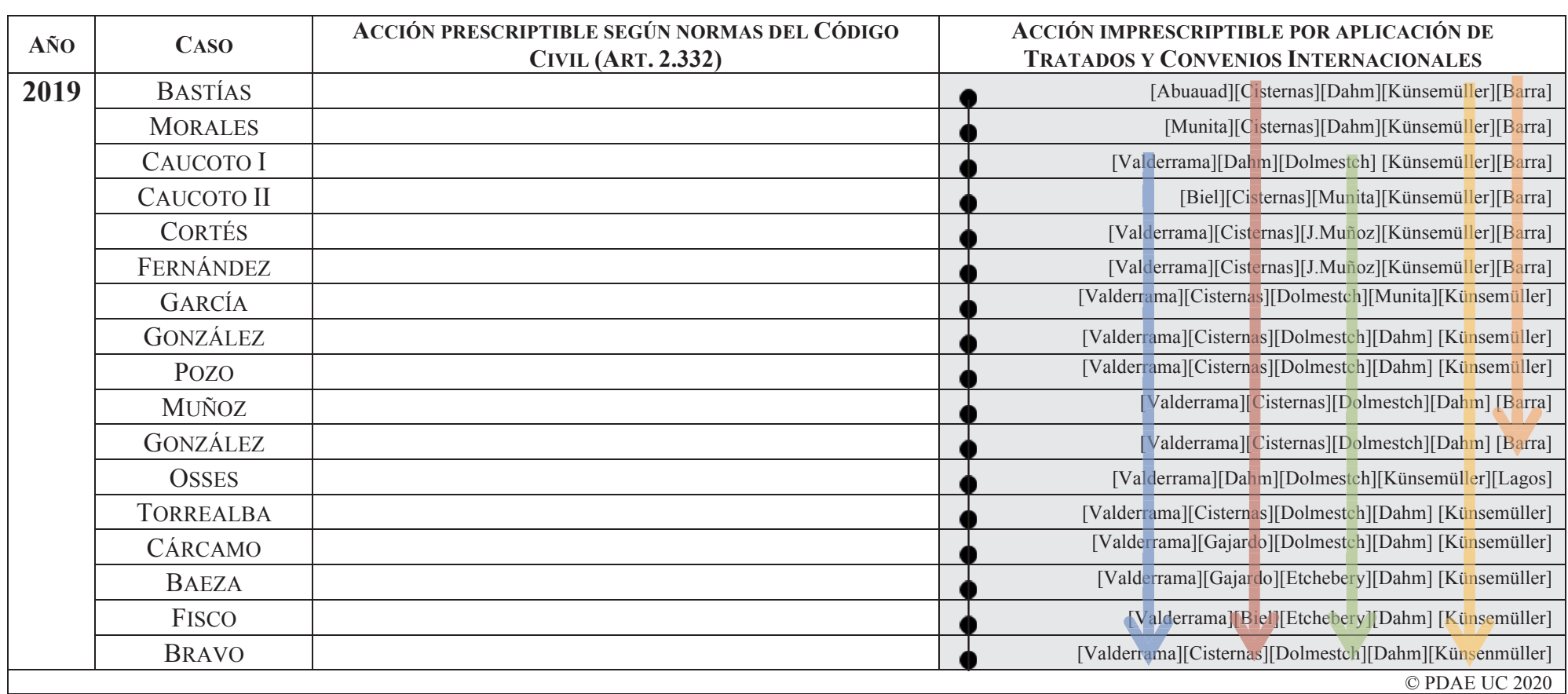


Gráfico 12.1. Comportamiento de sala: Régimen de los funcionarios a honorarios y supletoriedad del Código del Trabajo

\begin{tabular}{|c|c|c|c|}
\hline AÑo & $\begin{array}{c}\text { Casos QUe no aPlican el Código } \\
\text { Del Trabajo }\end{array}$ & $\begin{array}{c}\text { CASOS QUE DISTINGUEN LA } \\
\text { NATURALEZA DEL VÍNCULO, } \\
\text { APLICANDO EL CT Y EL EA, SEGÚN } \\
\text { CORRESPONDA } \\
\end{array}$ & Casos que aplican el Código CiVIL \\
\hline \multirow[t]{72}{*}{2019} & & SANDOVAL & \\
\hline & ZUÑIGA & [voto] & \\
\hline & ARENAS & [voto] & \\
\hline & \begin{tabular}{|l} 
RODRÍGUEZZ \\
\end{tabular} & [voto] & \\
\hline & & GARCÉS & \\
\hline & MUÑ̃Z & [voto] & \\
\hline & & ROJAS & \\
\hline & & DELGADO & \\
\hline & LIN & [voto] & \\
\hline & RISCO & [voto] & \\
\hline & ROMÁN & [voto] & \\
\hline & & MARTÍNEZ & \\
\hline & \begin{tabular}{|l|} 
REQUENA \\
\end{tabular} & [voto] & \\
\hline & ROA & [voto] & \\
\hline & MONTECINOS & [voto] & \\
\hline & TOBAR & [voto] & \\
\hline & PANDO & & \\
\hline & \begin{tabular}{|l|} 
TRUJILLO \\
\end{tabular} & [voto] & \\
\hline & \begin{tabular}{|l} 
ALVARADO \\
\end{tabular} & [voto] & \\
\hline & \begin{tabular}{|l|} 
URRUTIA \\
\end{tabular} & & \\
\hline & & GÓMEZ & \\
\hline & & MORA & \\
\hline & & CORTÉS & \\
\hline & CÁCERES & [voto] & \\
\hline & & BÁEZ & \\
\hline & & Sото & \\
\hline & \begin{tabular}{|l|} 
BARRERA \\
\end{tabular} & & \\
\hline & & QUINCHEL & \\
\hline & & ACEVEDO & \\
\hline & & SANDOVAL & \\
\hline & & ZORRICUETA & \\
\hline & RAMOS & & \\
\hline & MEDINA & & \\
\hline & & MORALES & \\
\hline & & ELSO & \\
\hline & MONTECINO & & \\
\hline & TONCIO & & \\
\hline & & CERÓN & \\
\hline & & SоTо & \\
\hline & DOMÍNGUEZ & [voto] & \\
\hline & CARRASCO & [voto] & \\
\hline & ZÚÑIGA & & \\
\hline & DEL SOLAR & [voto] & \\
\hline & SALINAS & & \\
\hline & \begin{tabular}{|l|} 
SIERRA \\
\end{tabular} & & \\
\hline & \begin{tabular}{|l|} 
AGUILERA \\
\end{tabular} & & \\
\hline & MUÑOZ & & \\
\hline & \begin{tabular}{|l|} 
CHEUQUELAF \\
\end{tabular} & [voto] & \\
\hline & \begin{tabular}{|l|} 
RAMÍREZ \\
\end{tabular} & [voto] & \\
\hline & ROMERO & & \\
\hline & \begin{tabular}{|l|} 
PALMA \\
\end{tabular} & & \\
\hline & \begin{tabular}{|l|} 
RIQUELME \\
\end{tabular} & & \\
\hline & TOLEDO & & \\
\hline & \begin{tabular}{|l|} 
COURTEN \\
\end{tabular} & [voto] & \\
\hline & \begin{tabular}{|l|} 
ELGUETA \\
\end{tabular} & [voto] & \\
\hline & VARGAS & [voto] & \\
\hline & ZAMORANO & [voto] & \\
\hline & GÁRATE & & \\
\hline & IBARRA & & \\
\hline & \begin{tabular}{|l} 
ARANCIBIA \\
\end{tabular} & & \\
\hline & SILVA & & \\
\hline & MANSILLA & [voto] & \\
\hline & \begin{tabular}{|l|} 
AGUIRRE \\
\end{tabular} & [voto] & \\
\hline & \begin{tabular}{|l|} 
PORRAS \\
\end{tabular} & [voto] & \\
\hline & DELTEIL & [voto] & \\
\hline & AGUILERA & [voto] & \\
\hline & MUÑOZ & [voto] & \\
\hline & \begin{tabular}{|l|} 
SÁNCHEZ \\
\end{tabular} & [voto] & \\
\hline & FAÚNDEZ & [voto] & \\
\hline & \begin{tabular}{|l|} 
CANALES \\
\end{tabular} & & \\
\hline & GARCÍA & & \\
\hline & & & (C) PDAE UC 2020 \\
\hline
\end{tabular}


Gráfico 12.2. Conducta de ministros y abogados integrantes: Funcionarios a honorarios y supletoriedad del Código del Trabajo

\begin{tabular}{|c|c|c|c|c|}
\hline AÑo & Caso & Casos QUE APLICAN EL Estatuto Administrativo & $\begin{array}{l}\text { CASOS QUE DISTINGUEN LA NATURALEZA DEL VINCULO, } \\
\text { APLICANDO EL CT Y EL EA, SEGÚN CORRESPONDA }\end{array}$ & Casos que aplican el Código Civil \\
\hline \multirow[t]{71}{*}{2019} & SANDOVAL & & [Chevesich][Blanco][A. Muñoz][Vivanco][Barra] & \\
\hline & ZÚÑIGA & [A. Muñoz][Biel][Matus][Munita] & [e revesich] & \\
\hline & ARENAS & 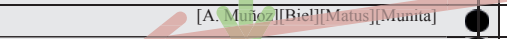 & [Chevesich] & \\
\hline & RODRÍGUEZ & 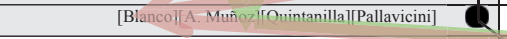 & [Chevesich] & \\
\hline & GARCÉS & & 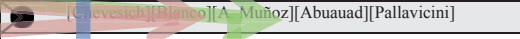 & \\
\hline & MUÑ̃Z & [Blim & [Chevesich] _ _ _ _ & \\
\hline & ROJAS & & 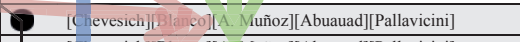 & \\
\hline & Delgado & & 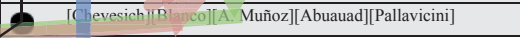 & \\
\hline & LIN & [Blane][A.M. & [Atánguiz] & \\
\hline & RISCO & 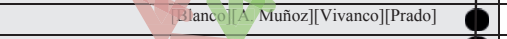 & [Chevesich] & \\
\hline & ROMÁN & [Blance][A, A & [Ghevesich] & \\
\hline & MARTÍNEZ & 2 & Douñoz][Etcheberry][De la Maza] & \\
\hline & REQUENA & 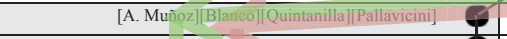 & [Chevesich] & \\
\hline & ROA & [A. Muñoz][Gönez][Quintanilla][Abuauad] & [Chevesich] & \\
\hline & MONTECINOS & [A. Muñoz][Gónezz][Quintanilla][Abuauad] & [Chevesich] & \\
\hline & TOBAR & [A. Muñoz][Go nezz][Quintanilla][Abuauad] & [Chevesich] & \\
\hline & PANDO & [Biel][A. Muñozz][B] anco)][Quintanilla][Abuauad] & & \\
\hline & TRUIILLO & [A Muñoz][Gó mez][Pallavicini][Abuauad] & [Chevesich] & \\
\hline & ALVARADO & [A. Muñozz][Gomezz][Quintanilla][Abuauad] & [Ch hevesich] & \\
\hline & URRUTIA & [A. Muñoz][B] & [Clevesich] & \\
\hline & GÓMEZ & & 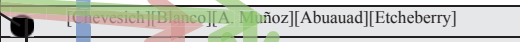 & \\
\hline & MORA & & [C] [evesich]/Me ins][A. Minozoz][Barra][Etcheberry] & \\
\hline & CORTÉS & & D. & \\
\hline & CÁCERES & 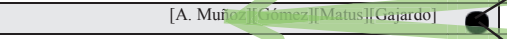 & [Chevesich] & \\
\hline & BÁEZ & & 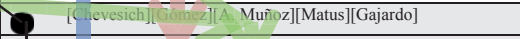 & \\
\hline & Sото & 22 & f & \\
\hline & BARRERA & 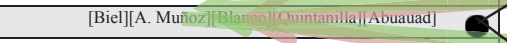 & 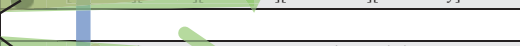 & \\
\hline & QUINCHEL & & 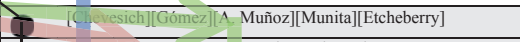 & \\
\hline & ACEVEDO & & 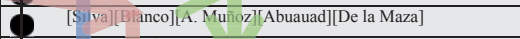 & \\
\hline & SANDOVAL & & 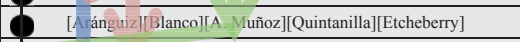 & \\
\hline & ZORRICUETA & & 2 val[Llanco][A. Muñoz][Abuauad][Etcheberry] & \\
\hline & RAMOS & [M. Silva][A. Muñ al[i tant & & \\
\hline & MEDINA & 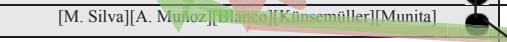 & +2 & \\
\hline & MORALES & - & 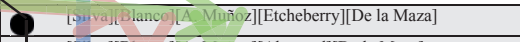 & \\
\hline & ELSO & 2 & 2 Is valri coo][A Murioz][Abuauad][De la Maza] & \\
\hline & MONTECINO & 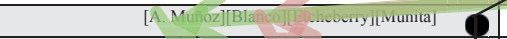 & [G levesich] & \\
\hline & TONCIO & 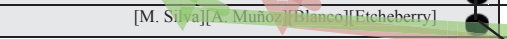 & [Chevesich] & \\
\hline & CERÓN & & 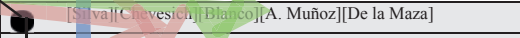 & \\
\hline & Sото & & . & \\
\hline & DOMÍNGUEZ & [M. Silva][[A. Muñoz] [Blar & & \\
\hline & CARRASCO & [Silva] A. Muñoz][Blanco][Barra] & [Ghevesich] & \\
\hline & ZÚÑIGA & [M. Silva]][A. Muioz][Blanco][De la Maza][Etcheberry] & & \\
\hline & DEL Solar & [A. Muñoz][Blanco][Barra][Etcheberry] & [Chevesich] & \\
\hline & SALINAS & [M. Silva]][A. Muñoz][Blaneo][De la Maza][Etcheberry] & 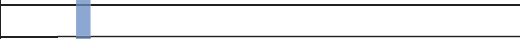 & \\
\hline & SIERRA & [M. Silva]][A. Muñoz][Blanco][Prado][Etcheberry] & 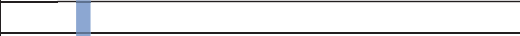 & \\
\hline & AGUILERA & [M. Silva]] [A. Muñoz] Blanco][Barra][Etcheberry] & & \\
\hline & MUÑOZ & [M. Silva]] A. Muñoz][Blanco][Barra][Etcheberry] & $\overline{2}$ & \\
\hline & CHEUQUELAF & [A. Muñoz][Bianco][Munita][Etcheberry] & [4, hevesich] & \\
\hline & RAMÍREZ & [M. Silva]][A. Muñoz][Blanco][Prado][Etcheberry] & & \\
\hline & ROMERO & [M. Silva][[A. Muñozz][Blanco][Abuauad][Etcheberry] & $T$ & \\
\hline & PALMA & [M. Silva]][A. Muñoz][Blanco][ABbuauad][Etcheberry] & 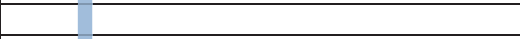 & \\
\hline & RIQUELME & [M. Silva]][A. Muñozz]/Blanco][Abuauad][Etcheberry] & & \\
\hline & TOLEDO & [M. Silva]][A. Muĩoz][B] lanco][De la Maza][Etcheberry] & - & \\
\hline & COURTEN & [Blanco] [Cisternas][Munita][Barra] & {$[$ [C evesich $]$} & \\
\hline & ELGUETA & [M. Silva][A. Muñoz][De la Maza][González] & [c evesich $]$ & \\
\hline & VARGAS & [M. Silva][A] Muñoz][De la Maza][González] & [C evesich] & \\
\hline & ZAMORANO & [Blanco] [Cisternas][Munita][Barra] & [C evesich] & \\
\hline & GÁRATE & [M. Silva]][A. Muñoz][Barra][De la Maza][Repetto] & & \\
\hline & IBARRA & [M. Silva][A. Muñozz][Gonzalezz][Quintanilla][Etcheberry] & - & \\
\hline & ARANCIBIA & [M. Silva][A. Muñoz][Pallavicini][De la Maza][Repetto] & & \\
\hline & SILVA & [A. Muñoz][Pradid][De la Maza][Repetto][Etcheberry] & & \\
\hline & MANSILLA & [Brito| [A. Muñoz][De la Maza][Pallavicini] & [C evesich] & \\
\hline & AGUIRRE & [Brito||A. Muñoz][De la Maza][Pallavicini] & [C evesich] & \\
\hline & PORRAS & [Brito][A. Muñoz][De la Maza][Pallavicini] & [C evesich] & \\
\hline & DELTEIL & [A. Muñozz][Prado][Barra][Etcheberry] & [C evesich] & \\
\hline & AGUILERA & [A. Muñozz][Abuauad][De la Maza][Repetto] & [C evesich] & \\
\hline & MUÑOZ & [A. Muñozz][Abuauad][De la Maza][Repetto] & {$[\mathrm{C}$ evesich] } & \\
\hline & SÁNCHEZ & [M. Silva]][A. Muñoz][Barra][Repetto] & [aley & \\
\hline & FAÚNDEZ & [M. Silva]][A. Muñoz][Barra][Repetto] & {$[$ Ç/evesich $]$} & \\
\hline & CANALES & [Gajardo]/M. Silva]][Lagos][Mera][Repetto] & & \\
\hline & GARCÍA & [M. Silva][A. Muñoz][Gonzalezz][Prado][Repetto] & & \\
\hline
\end{tabular}


Gráfico 13.1 . Comportamiento de la sala: Térming anticipado de empleo a contrata
Grafico 13.1. Comportaniento de la sala: Termino anticipado de empleo a contrata

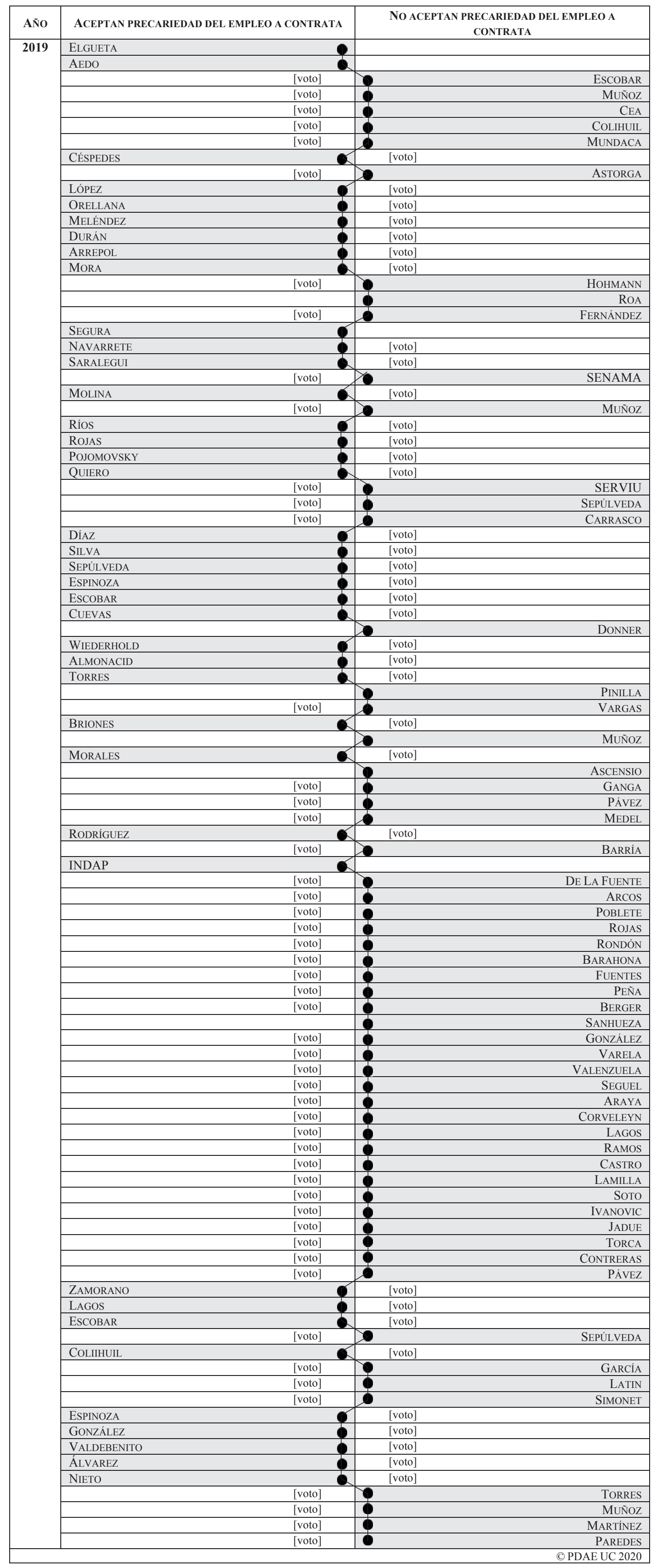

ReDAE Revista de Derecho Administrativo Económico, № 31 [enero-junio 2020] pp. 251-299 


\begin{tabular}{|c|c|}
\hline AÑo & CASO \\
\hline 2019 & ELGUETA \\
\hline & AEDO \\
\hline & ESCOBAR \\
\hline & MUÑOZ \\
\hline & CEA \\
\hline & COLIHUIL \\
\hline & MUNDACA \\
\hline & CÉSPEDES \\
\hline & ASTORGA \\
\hline & LÓPEZ \\
\hline & ORELLANA \\
\hline & MELÉNDEZ \\
\hline & DURÁN \\
\hline & ARREPOL \\
\hline & MORA \\
\hline & HOHMANN \\
\hline & ROA \\
\hline & FERNÁNDEZ \\
\hline & SEGURA \\
\hline & NAVARRETE \\
\hline & SARALEGUI \\
\hline & SENAMA \\
\hline & MoLina \\
\hline & MUÑOZ \\
\hline & Ríos \\
\hline & ROJAS \\
\hline & POJOMOVSKY \\
\hline & QUIERO \\
\hline & SERVIU \\
\hline & SEPÚLVEDA \\
\hline & CARRASCO \\
\hline & DÍAZ \\
\hline & SILVA \\
\hline & SEPÚLVEDA \\
\hline & ESPINOZA \\
\hline & ESCOBAR \\
\hline & CuEvas \\
\hline & DONNER \\
\hline & WIEDERHOLD \\
\hline & ALMONACID \\
\hline & TORRES \\
\hline & PINILLA \\
\hline & VARGAS \\
\hline & BRIONES \\
\hline & MUÑOZ \\
\hline & MORALES \\
\hline & ASCENSIO \\
\hline & GANGA \\
\hline & PÁVEZZ \\
\hline & MEDEL \\
\hline & RODRÍGUEZ \\
\hline & BARRÍA \\
\hline & INDAP \\
\hline & DE LA FuENTE \\
\hline & ARCOS \\
\hline & POBLETE \\
\hline & ROJAS \\
\hline & RONDÓN \\
\hline & BARAHONA \\
\hline & FUENTES \\
\hline & PEÑa \\
\hline & BERGER \\
\hline & SANHUEZA \\
\hline & GONZÁLEZ \\
\hline & VARELA \\
\hline & $\begin{array}{l}\text { VALENZUELA } \\
\end{array}$ \\
\hline & $\begin{array}{l}\text { SEGUEL } \\
\end{array}$ \\
\hline & ARAYA \\
\hline & CORVELEYN \\
\hline & LAGOS \\
\hline & RAMOS \\
\hline & CASTRO \\
\hline & LAMILLA \\
\hline & Sото \\
\hline & IVANOVIC \\
\hline & JADUE \\
\hline & TORCA \\
\hline & CONTRERAS \\
\hline & PÁVEZ \\
\hline & ZAMORANO \\
\hline & LAGOS \\
\hline & ESCOBAR \\
\hline & SEPÚLVEDA \\
\hline & CoLIHUIL \\
\hline & GARCÍA \\
\hline & LATIN \\
\hline & SIMONET \\
\hline & ESPINOZA \\
\hline & GONZÁLEZ \\
\hline & VALDEBENITO \\
\hline & ÁlVVAREZ \\
\hline & NIETO \\
\hline & TORRES \\
\hline & MuÑOZ \\
\hline & MARTINEZZ \\
\hline & PAREDES \\
\hline
\end{tabular}


Gráfico 14.1. Comportamiento de la sala: Desviación de poder en las desvinculaciones de funcionarios a contrata

\begin{tabular}{|c|c|c|}
\hline Año & $\begin{array}{l}\text { RECONOCE DESVIACIÓN DE PODER COMO VICIO DE LEGALIDAD EN } \\
\text { LAS DESVINCULACIONES/TRASLADOS DE FUNCIONARIOS }\end{array}$ & $\begin{array}{l}\text { DESCONOCE DESVIACIÓN DE PODER COMO VICIO DE LEGALIDAD EN } \\
\text { LAS DESVINCULACIONES/TRASLADOS DE FUNCIONARIOS }\end{array}$ \\
\hline \multirow[t]{12}{*}{2019} & Bustos & \\
\hline & MUNDACA & [voto] \\
\hline & [voto] & LÓPEZ \\
\hline & [voto] & MELÉNDEZ \\
\hline & [voto] & CONDORI \\
\hline & [voto] & AGUILERA \\
\hline & GANGA & [voto] \\
\hline & BARRÍA & [voto] \\
\hline & RONDÓN & [voto] \\
\hline & FUENTES & [voto] \\
\hline & BERGER & [voto] \\
\hline & BARRERA & \\
\hline & & (C) PDAE UC 2020 \\
\hline
\end{tabular}

Gráfico 14.2. Comportamiento de ministros y abogados integrantes: Desviación de poder en las desvinculaciones de funcionarios a contrata

\begin{tabular}{|c|c|c|c|}
\hline AÑ̃o & CASO & $\begin{array}{c}\text { RECONOCE DESVIACIÓN DE PODER COMO VICIO DE LEGALIDAD EN } \\
\text { LAS DESVINCULACIONES/TRASLADOS DE FUNCIONARIOS }\end{array}$ & $\begin{array}{c}\text { DESCONOCE DESVIACIÓN DE PODER COMO VICIO DE LEGALIDAD EN } \\
\text { LAS DESVINCULACIONES/TRASLADOS DE FUNCIONARIOS } \\
\end{array}$ \\
\hline \multirow[t]{12}{*}{2019} & BUSTOS & [S. Muñoz] [Vivanco] [Prado] [Aránguiz] [Sandoval] & \\
\hline & MunDACA & [S. Muñoz] [Vivanco] [Prado] [Aránguiz] & [Sandoval] \\
\hline & LÓPEZ & [S. Muñoz] [Vivạnco] & [Aránguiz] [Prado] [Sandoval] \\
\hline & MELÉNDEZ & [S. Muñoz] [Pradö] & [De la Maza] [Pierry] [Sandoval] \\
\hline & CONDORI & [S. Muñoz] & [Yivanco] [Blanco] [Prado] [Munita] \\
\hline & AGUILERA & [S. Muñoz] & [Vivanco] [Blancol [Prado] [Sandoval] \\
\hline & GANGA & [S. Muñoz] [Vivanco] [Prallo] & [Pallavicini] [Sandoval] \\
\hline & BARRÍA & [S. Muñoz] [Vivanco] [Prado] & [Pallavicini] [Sandoval] \\
\hline & RONDÓN & [S. Muñoz] [Pierry] [Prado] [Etcheberry] & [Sandoval] \\
\hline & FUENTES & [S. Muñoz] [Vivanco] [Prado] [Blanco] & [Sandoval] \\
\hline & BERGER & [Fuentes] [J. Muñoz] [Quintanilla] [Munita] & [Sandoval] \\
\hline & BARRERA & [S. Muñoz] [Vivanco] [Aránguiz] [Pallavicini] [Sandoval] & \\
\hline
\end{tabular}


Gráfico 15.1. Comportamiento de la sala: Recurso de protección como vía idónea en casos de desvinculación de funcionarios a contrata

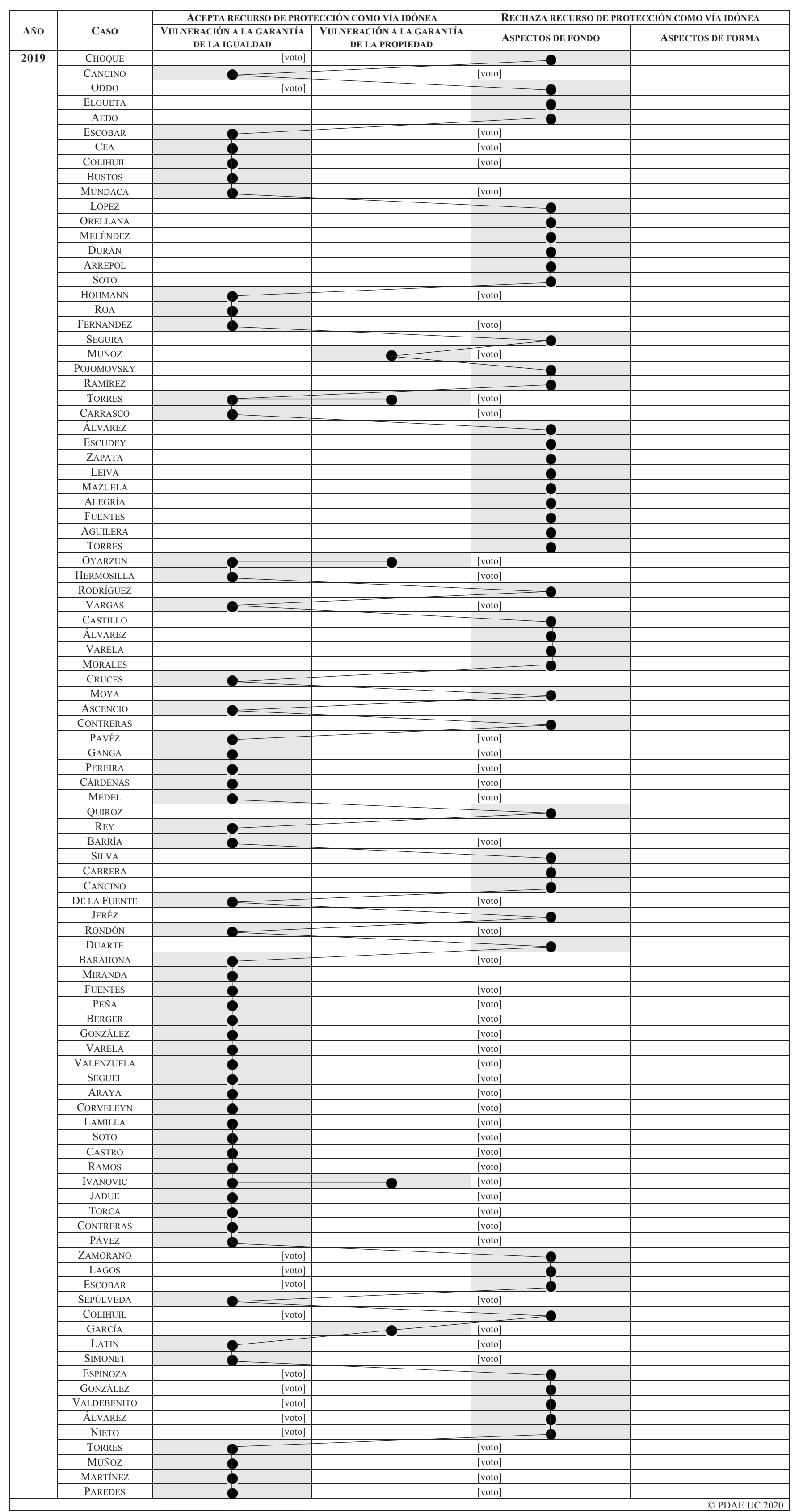

ReDAE Revista de Derecho Administrativo Económico, № 31 [enero-junio 2020] pp. 251-299 
Gráfico 15.2. Comportamiento de ministros y abogados integrantes: Recurso de protección como vía idónea en casos de desvinculación de funcionarios a contrata

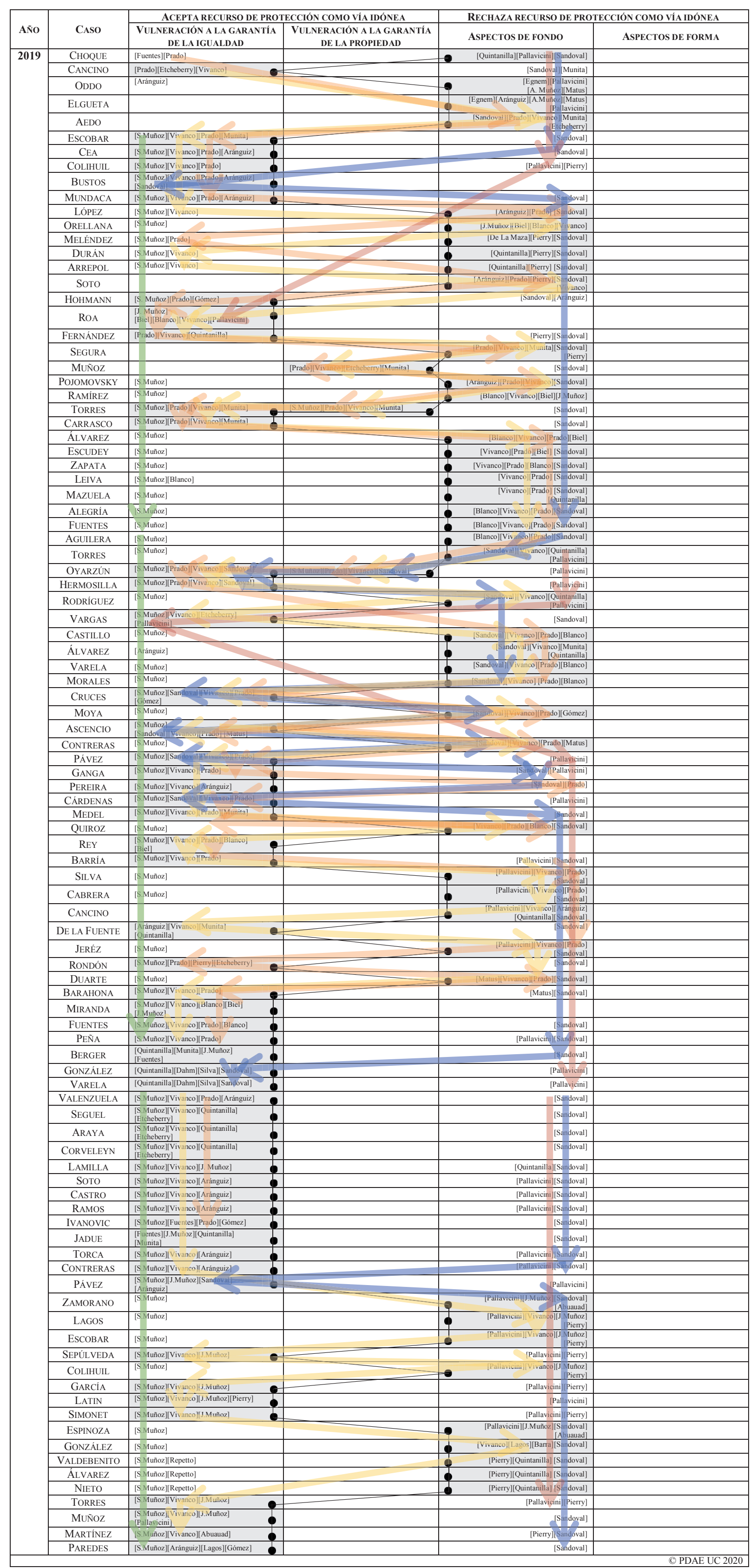

ReDAE Revista de Derecho Administrativo Económico, № 31 [enero-junio 2020] pp. 251-299 
Gráfico 16.1. Comportamiento de la sala: Regularización de derechos de aguas

\begin{tabular}{|c|c|c|c|}
\hline Ã்̃ & ACEPTANDO & \multicolumn{2}{|c|}{ RECHAZANDO } \\
\hline \multirow[t]{4}{*}{2019} & & $\Omega$ & ESVAL I \\
\hline & & & ESVAL II \\
\hline & MORENO & [voto] & \\
\hline & LAY SON & [voto] & \\
\hline
\end{tabular}

Gráfico 16.2. Comportamiento de ministros y abogados integrantes: Regularización de derechos de aguas

\begin{tabular}{|c|c|c|c|}
\hline AÑo & CASO & MINISTROS ACEPTANDO REGULARIZACIÓN & MINISTROS RECHAZANDO REGULARIZACIÓN \\
\hline \multirow[t]{4}{*}{2019} & ESVAL I & & [Pallavicini] [Biel] [Gajardo] [Vivąnco] [Sandoval] \\
\hline & ESVAL II & & [Pallavícinil [Riel] [Gajardo] [Vivañco] [Sandoval] \\
\hline & MORENO & [Blanco] [Vivancé] [S. Muñoz] & [iviunta] [Prado] \\
\hline & LAY SON & [Blanco] [Vivangeo] [S. Muñôz] [Bie!', & [Pierry] \\
\hline
\end{tabular}

Gráfico 18.1. Comportamiento de la sala: Plazo para que tercero absoluto pueda solicitar invalidación ambiental

\begin{tabular}{|c|c|c|}
\hline AÑo & APLICA PLAZO DE DOS AÑOS & APLICA PLAZO DE TREINTA DÍAS \\
\hline 2019 & COMUNIDAD & \\
\hline \multicolumn{2}{|c|}{ O PDAE UC 2020 } \\
\hline
\end{tabular}

Gráfico 18.2. Comportamiento de ministros y abogados integrantes: Plazo para que tercero absoluto pueda solicitar invalidación ambiental

\begin{tabular}{|c|c|c|c|}
\hline AÑo & CASO & APLICA PLAZO DE DOS AÑOS & APLICA PLAZO DE TREINTA DÍAS \\
\hline $\mathbf{2 0 1 9}$ & COMUNIDAD & [S. Muñoz] [Sandoval] [Aránguiz] [Vivanco] [Quintanilla] & \\
\hline \multicolumn{2}{|l|}{} \\
\hline
\end{tabular}




\section{Conclusiones}

\section{Resultados distintos en 2019}

El resultado de la revisión de la jurisprudencia de la Corte Suprema, en veinte temas en 2019 (en los 15 temas en que se registraron fallos, efectivamente), en cuanto a su uniformidad o vacilación es distinto al del primer estudio, que cubrió la década anterior (2008-2018). La jurisprudencia resultante es notoriamente más lineal en cuanto a las sentencias que emiten las salas de la CS. En cuanto a la conducta de sus ministros y abogados integrantes, también tiende más a la linealidad pero persisten algunos zigzagueos individuales. La Corte Suprema, entonces, ahora exhibe una nueva conducta dirigida a ofrecer precedentes, y se aprecia un aumento de temas con jurisprudencia uniforme. No obstante que se mantienen las vacilaciones en algunos otros temas.

\section{Comportamiento de las salas: tres conductas se aprecian}

Podemos esquematizar la conducta de las Salas de la CS así: i) hay casos en que la jurisprudencia de la década anterior era lineal, y sigue siéndolo (no se aprecia la conducta inversa: que antes fuese lineal y ahora sea zigzagueante); ii) hay casos en que la jurisprudencia en la década anterior era zigzagueante y ahora es lineal; esto es, la CS deja de zigzaguear; y, iii) hay casos en que la jurisprudencia era zigzagueante y sigue siéndolo. Se puede apreciar en los gráficos respectivos.

a) temas en que la jurisprudencia sigue siendo lineal. Hay temas en que la jurisprudencia fue uniforme en el período anterior y sigue siéndolo en 2019. Es el caso de los temas 1 (cómputo de plazos), 3 (audiencia previa), 5 (agotamiento), 6 (prescripción acción nulidad) y 8 (precepción acción de responsabilidad).

b) temas en que la jurisprudencia ahora es uniforme. Hay temas en que la jurisprudencia fue zigzagueante en el período anterior y deja de serlo en 2019. Es el caso de los temas 2 (plazos fatales), 4 (plazo acción sancionatoria), 7 (cómputo plazos), 9 (indemnización por responsabilidad crímenes lesa humanidad), 12 (funcionarios a honorarios), 14 (desviación de poder) y 15 (protección como vía idónea).

c) temas en que la jurisprudencia continúa zigzagueando. Hay temas en que la jurisprudencia sigue zigzagueando, como en el período anterior. Es el caso de los temas 13 (contratas), 16 (regularización derechos aguas) y 18 (invalidación ambiental).

En suma, puede decirse que, durante 2019, hay más temas en que la jurisprudencia ha sido admirablemente lineal y menos temas en los que lamentablemente se mantiene el zigzagueo. 


\section{Comportamiento de ministros y abogados integrantes}

La mayor linealidad de las salas observadas se debe, seguramente, a una conducta más lineal de sus ministros y abogados integrantes; pero también se mantienen algunas conductas erráticas de algunos de ellos. Al respecto, podemos observar tres tipos de conductas de ministros y abogados integrantes (las que se pueden apreciar en los gráficos respectivos):

i) casos de ministros y abogados integrantes que anteriormente eran muy zigzagueantes, si bien ahora siguen zigzagueando casi todos lo hacen en menos ocasiones;

ii) hay ministros y abogados integrantes que anteriormente eran levemente zigzagueantes, tienden a ofrecer conductas más lineales;

iii) son minoritarios los ministros que ofrecen gran linealidad y uniformidad en sus votos; y un solo caso de una ministra que no zigzaguea nunca.

\section{IV. ¿Razones del cambio? ¿Decisión institucional?}

No hay evidencia alguna de que la Corte Suprema (en Pleno) haya adoptado alguna decisión institucional para enfrentar el zigzagueo denunciado en el Estudio anterior (y continuado ahora). No hay evidencia alguna, por otra parte, que las salas respectivas hayan adoptado decisiones internas dirigidas a evitar las vacilaciones. Pero sí resulta bien ostensible que los resultados evidenciados en este nuevo Estudio se debe a un cambio de actitud de ministros y abogados integrantes; pues hay temas en que la CS ratifica su jurisprudencia lineal (no hay retrocesos observables) y otros temas en que la CS antes fue zigzagueante, y ahora deja de serlo. Es un verdadero giro el que se produce en la jurisprudencia, por ejemplo, en tres casos a partir de mediados del año pasado (obsérvese los gráficos respectivos). Así:

i) es notorio lo que ocurrió en la Cuarta Sala en el tema 12 (funcionarios a honorarios): tanto en el anterior estudio y ahora hasta mayo de 2019 siguió siendo zigzagueante; pero, a partir de junio dejó de vacilar y ofreció de manera admirable una sola línea has fin de año; y,

ii) también es ostensible lo que ocurrió en la Tercera Sala en los temas 14 (desviación de poder) y 15 (vía idónea) en los que, desde mayo y junio, respectivamente, la sala dejó de zigzaguear. Lo anterior lamentablemente no tiene mayor efecto en el tema 13 (contratas), vinculado con los anteriores, en que la sala sigue zigzagueando.

\section{V. ¿Algún mérito que atribuir al estudio?}

En fin, si nuestro Estudio de Líneas y vacilaciones de la jurisprudencia 20082018 significó para los jueces de la CS, en alguna medida, una forzada e inédita autoobservación de sus conductas, acaso haya servido también como un impulso para este cambio que hoy ofrece la jurisprudencia. Cambios estos que, espero, los llene ahora de satisfacción, porque demuestra un mejor desempeño institucional de la CS. 


\section{Anexo de Sentencias [Total de casos: 333]}

\section{Conflictos durante el procedimiento administrativo}

1. Cómputo de plazos durante la tramitación del procedimiento administrativo [7 casos]

Frigorífico Karmac SpA con Inspección Comunal del Trabajo de Lautaro (2019): CS, 8 enero 2019 (Rol N 22995-2018), 3a Sala. M: S. Muñoz (r), Prado, Vivanco; Al: Etcheberry, Gómez [protección].

Eaton Industries Chile SpA con Inspección Comunal del Trabajo Norte Chacabuco (2019): CS, 28 enero 2019 (Rol No 23259-2018), 3a Sala. M: S. Muñoz, Sandoval, Vivanco; Al: Matus (r), Barra [protección].

Embotelladora Andina S.A. con Inspección Provincial del Trabajo de Copiapó (2019): CS, 1 julio 2019 (Rol No 7515-2019), 3a Sala. M: Sandoval, Aránguiz, Vivanco (r); Al: Munita, Pierry [apelación].

Distribuidora Vergio S.A. con Flores Gallegos, Andrés y Municipalidad de Tomé (2019): CS, 15 julio 2019 (Rol N 20589-2018), 3a Sala. M: S. Muñoz (r), Sandoval, Vivanco; Al: Pierry, Pallavicini [casación].

Red de Televisión Chilevisión S.A. y la Universidad de Chile con M de la Corte de Apelaciones de Santiago (2019): CS, 19 agosto 2019 (Rol N 4559-2019), 3a Sala. M: S. Muñoz, Sandoval, Aránguiz ( $r$ ), Prado, Vivanco [queja].

Red UC Christus Servicios Clínicos SpA con Superintendencia de Salud (2019): CS, 4 septiembre 2019 (Rol N² 20420-2019), 3a Sala. M: S. Muñoz, Sandoval, Aránguiz; Al: Quintanilla (r), Pierry [casación].

Sanzone Riili, Roberto Gabriel con Ministerio de Obras Públicas, Dirección General de Aguas (2019): CS, 22 octubre 2019 (Rol No 31256-2018), 3a Sala. M: S. Muñoz, Sandoval, Aránguiz, Vivanco; Al: Quintanilla (r) [casación].

2. Plazos fatales para que la Administración responda solicitudes del ciudadano [3 casos]

Almonacid Merino, Gonzalo con Municipalidad de Caldera (2019): CS, 3 enero 2019 (Rol N²4935-2018), 3a Sala. M: Sandoval, Vivanco, Biel; Al: Pallavicini, Gajardo (r) [protección].

Clínica Alemana de Temuco con Superintendencia de Salud (2019): CS, 16 enero 2019 (Rol N²57-2019), 3a Sala. M: Sandoval, Aránguiz, Vivanco, Prado; Al: Etcheberry (sr) [reclamación].

Reveco Hormazábal Pedro con Unidad de Análisis Financiero (2019): CS, 26 marzo 2019 (Rol N²3056-2018), 3a Sala. M: S. Muñoz (d), Sandoval, Prado, Vivanco; Al: Pallavicini (r) (p) [reclamación].

3. Audiencia previa como requisito esencial del procedimiento de invalidación [3 casos]

Olate Berríos, Ema con Gatica Barros, Jaime (2019): CS, 8 mayo 2019 (Rol N²0662-2018), 3a Sala. M: Muñoz, Sandoval, Prado (r), Vivanco; Al: Munita [protección]

Corporación de Educación Arte y Cultura CEAC con Ministerio de la Cultura las Artes y el Patrimonio (2019): CS, 1 octubre 2019 (Rol N²1237-2019), 3ª Sala. M: Aránguiz, S. Muñoz, Sandoval, Vivanco (r); Al: Pallavicini [protección].

Comité Pro Defensa del Patrimonio Histórico y Cultura de Viña del Mar con I. Municipalidad de Concón (2019): CS, 19 noviembre 2019 (Rol N²2221-2018), 3a Sala. M: S. Muñoz, Sandoval (r), Aránguiz, Vivanco; Al: Pierry [casación]

4. Plazo de la Administración para ejercer potestad sancionatoria [3 casos] Fisco de Chile con Pozos Profundos S.A. (2019): CS, 28 marzo 2019 (Rol No 2727-2019), $3^{\text {a }}$ Sala. M: S. Muñoz (r), Blanco, Vivanco, Biel, J. Muñoz [casación]. 
Opko Chile S.A. con Instituto de Salud Pública (2019): CS, 10 septiembre 2019 (Rol № 16230-2018), $3^{a}$ Sala. M: Aránguiz, Prado (d), Vivanco; Al: Quintanilla, Barra (r) [casación].

Laboratorios Pharma Investi de Chile S.A. con Instituto de Salud Pública (2019): CS, 29 noviembre 2019 (Rol No 16231-2018), 3a Sala. M: S. Muñoz (p), Sandoval (p), Aránguiz (p), Prado; Fiscal judicial: Sáez (p); Al: Lagos (d), Pallavicini (d) (r) [casación].

5. Agotamiento de la vía administrativa e interrupción del plazo para ejercer posteriores recursos jurisdiccionales [2 casos]

Pineda Peña, Mario con Soto Isla, Hermes (2019): CS, 13 agosto 2019 (Rol N6007-2019), 3a Sala. M: S. Muñoz, Sandoval, Aránguiz, Prado, Vivanco (r) [protección].

Lagos Lagos, Andrea con Superintendencia de Seguridad Social (2019): CS, 13 septiembre 2019 (Rol N²2950-2019), 3a Sala. M: S. Muñoz (p), Sandoval, Aránguiz. Al: Munita (r), Pierry [protección]

\section{Conflictos al presentar recursos jurisdiccionales}

6. $\quad$ Plazo de prescripción de la acción de nulidad administrativa [2 casos]

Pesquera B y B Limitada con Fisco de Chile (2019): CS, 29 julio 2019 (Rol No 29254-2018), $3^{a}$ Sala. M: S. Muñoz (p), Prado, Sandoval, Vivanco; Al: De la Maza (r) [casación]

Comunidad Habitacional Villa Aconcagua con Servicio de Vivienda y Urbanización (2019): CS, 4 septiembre 2019 (Rol Nº15489-2018), 3a Sala. M: S. Muñoz (d), Sandoval, Aránguiz (r), Vivanco; Al: Aránguiz [casación].

7. Cómputo del plazo para presentar recursos jurisdiccionales contra actos administrativos [7 casos]

Miranda Vidal, Shalim Heriberto con Municipalidad de Ancud (2019): CS, 8 enero 2019 (Rol No3541-2018), $3^{\text {a }}$ Sala. M: S. Muñoz, Chevesich (p), Prado; Al: Pierry (r), Pallavicini [casación].

Egaña Rasse, Miguel con I. Municipalidad de Cartagena (2019): CS, 25 marzo 2019 (Rol N³3566-2018), $3^{a}$ Sala. M: Aránguiz (r), Prado, Sandoval, Vivanco; Al: Etcheberry [casación].

Distribuidora Vergio S.A. con Municipalidad de Tomé (2019): CS, 15 julio 2019 (Rol N²0589-2018), $3^{a}$ Sala. M: S. Muñoz (r), Sandoval, Vivanco; Al: Pierry, Pallavicini [reclamación].

Red de Televisión Chilevisión S.A. y otro con Ministros de la Corte de Apelaciones de Santiago (2019): CS, 19 agosto 2019 (Rol No 4559-2019), 3a Sala. M: S. Muñoz, Sandoval, Aránguiz (r), Prado, Vivanco [recurso de queja].

Red UC Christus Servicios Clínicos SpA con Superintendencia de Salud (2019): CS, 4 septiembre 2019 (Rol N²0420-2019), 3ª Sala. M: S. Muñoz, Sandoval, Aránguiz; Al: Quintanilla (r), Pierry [casación].

Sanzone Riili, Roberto con Dirección General de Aguas (2019): CS, 22 octubre 2019 (Rol No 31256-2018), 3a Sala. M: S. Muñoz, Sandoval, Aránguiz, Vivanco; Al: Quintanilla (r) [casación].

Televisión Nacional de Chile con Ministros de la Corte de Apelaciones de Santiago (2019):

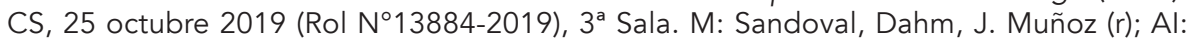
Munita, Gajardo [queja].

8. Prescripción de la acción indemnizatoria de responsabilidad patrimonial de la Administración [5 casos]

Alegría Gómez, Hortensia con Fisco de Chile (2019): CS, 20 marzo 2019 (Rol Nº 53652018), 3a Sala. M: S. Muñoz (p), Sandoval, Aránguiz; Al: Munita, Abuauad (r) [casación]. 
Alcamino Menichetti, Carolina con Junta Nacional de Jardínes Infantiles (2019): CS, 12 junio 2019 (Rol No 4288-2019), 3a Sala. M: S. Muñoz (r) (p), Prado, Sandoval, Vivanco; Al: Matus [casación].

Laboratorios Chile S.A. con Fisco de Chile (2019): CS, 12 agosto 2019 (Rol No 12911-2018), 3a Sala. M: S. Muñoz, Sandoval, Vivanco; Al: Quintanilla (r), Pallavicini [casación].

Olate Pérez, Ercira y otros con Servicio de Salud Concepción (2019): CS, 26 septiembre 2019 (Rol No18743-2018), 3a Sala. M: S. Muñoz (p), Sandoval, Prado, Vivanco (r); Al: Pierry [casación].

Báez Vílchez, Rosa con Servicio de Salud Talcahuano (2019): CS, 8 noviembre 2019 (Rol No 14909-2019), 3a Sala. M: S. Muñoz (p), Sandoval, Aránguiz, Vivanco (r); Al: Pallavicini [casación].

9. Prescripción acción indemnizatoria de crímenes de lesa humanidad por agentes del Estado [17 casos]

Bastías Kessi, Carlos con Fisco de Chile (2019): Corte Suprema, 15 enero 2019 (Rol No 20362-2018), $2^{a}$ Sala. M: Künsemüller, Cisternas, Dahm (r); Al: Abuauad, Barra [casación].

Morales Saavedra, Hugo y otro con Fisco de Chile (2019): Corte Suprema, 29 enero 2019 (Rol No 12636-2018), $2^{a}$ Sala. M: Künsemüller, Cisternas, Dahm; Al: Barra (r), Munita [casación].

Caucoto Pereira, Nelson Guillermo con Fisco de Chile I (2019): Corte Suprema, 21 febrero 2019 (Rol No 3363-2019), $2^{\text {a }}$ Sala. M: Dolmestch, Künsemüller, Valderrama, Dahm; Al: Barra (sr) [casación].

Caucoto Pereira, Nelson con Fisco de Chile II (2019): Corte Suprema, 21 febrero 2019 (Rol No 15402-2018), 2a Sala. M: Künsemüller, Cisternas, Biel; Al: Munita (r), Barra [casación].

Cortés Cortés, María con Fisco de Chile (2019): Corte Suprema, 25 febrero 2019 (Rol N 29251-2018), $2^{\text {a }}$ Sala. M: Künsemüller, Cisternas, Valderrama, J. Muñoz; Al: Barra (sr) [casación].

Fernández Barra, Mercedes y otros con Fisco de Chile (2019): Corte Suprema, 26 febrero

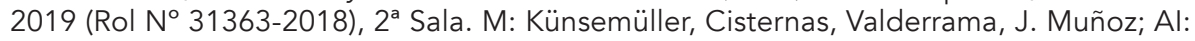
Barra (sr) [casación].

García López, Ruth y otros con Fisco de Chile (2019): Corte Suprema, 4 marzo 2019 (Rol No 4521-2019), $2^{\text {a }}$ Sala. M: Dolmestch, Künsemüller, Cisternas, Valderrama; Al: Munita (sr) [casación].

González Pérez, Juan con Fisco de Chile (2019): Corte Suprema, 26 marzo 2019 (Rol No 29463-2018), $2^{a}$ Sala. M: Dolmestch, Künsemüller, Cisternas, Valderrama (r), Dahm [casación].

Pozo Cabezas, Margarita con Fisco de Chile (2019): Corte Suprema, 26 marzo 2019 (Rol $N^{\circ}$ 29944-2018), $2^{a}$ Sala. M: Dolmestch, Künsemüller, Cisternas, Valderrama (r), Dahm [casación].

Muñoz Odgers, Marta y otros con Fisco de Chile (2019): Corte Suprema, 13 mayo 2019 (Rol No 31605-2018), $2^{\text {a }}$ Sala. M: Dolmestch, Cisternas (r), Valderrama, Dahm; Al: Barra [casación].

González Pérez, Daniel Aurelio con Fisco de Chile (2019): Corte Suprema, 28 mayo 2019 (Rol No 31766-2018), $2^{\text {a }}$ Sala. M: Dolmestch, Cisternas, Valderrama (r), Dahm; Al: Barra [casación].

Osses Beltrán, Agneo José con Fisco de Chile (2019): Corte Suprema, 20 agosto 2019 (Rol $N^{\circ}$ 29448-2018), 2a Sala. M: Dolmestch, Künsemüller (r), Valderrama, Dahm; Al: Lagos [casación].

Torrealba Pasten, Guillermo y Fuentes Morales, Marcia con Medina Aldea, Luis Alberto (2019): Corte Suprema, 26 septiembre 2019 (Rol No 8318-2018), 2a Sala. M: Dolmestch, Künsemüller, Cisternas (r), Valderrama, Dahm [casación].

Cárcamo Barría, José Enrique con Fisco de Chile (2019): Corte Suprema, 11 octubre 2019 (Rol No 17842-2019), $2^{\text {a }}$ Sala. M: Dolmestch, Künsemüller, Valderrama, Dahm; Al: Gajardo (r) [casación]. 
Baeza González, José Luis con Fisco de Chile (2019): Corte Suprema, 4 noviembre 2019 (Rol No 19210-2019), $2^{\text {a }}$ Sala. M: Künsemüller, Valderrama, Dahm; Al: Etcheberry (r), Gajardo [casación].

Fisco de Chile con Pinochet Ugarte, Augusto y otros (2019): Corte Suprema, 5 noviembre 2019 (Rol No 4227-2018), 2a Sala. M: Künsemüller, Valderrama, Dahm (r), Biel; Al: Etcheberry [casación].

Bravo Espinoza, Nelson y otros con Fisco de Chile (2019): CS, 14 noviembre 2019 (Rol N²0520-2018), 2 ${ }^{a}$ Sala. M: Dolmestch, Künsenmüller, Cisternas (r), Valderrama, Dahm. [casación]

10. Legitimación activa para ejercer la acción de protección [no se registraron casos en 2019]

11. Procedencia y alcance de la acción de mera certeza [no se registraron casos en 2019]

III. Conflictos relativos a la estabilidad de los trabajadores en la administración

\section{Funcionarios a honorarios y supletoriedad Código del Trabajo [71 casos]}

Sandoval Vergara, Paula con Municipalidad de Tomé (2019): CS, 2 enero 2019 (Rol No 23013-2018), $4^{\text {a }}$ Sala. M: Blanco, Chevesich, A. Muñoz, Vivanco; Al: Barra (sr) [unificación de jurisprudencia laboral].

Zúñiga Meza, María con Municipalidad de Hualpén (2019): CS, 2 enero 2019 (Rol No 23016-2018), $4^{\text {a }}$ Sala. M: Chevesich (p), A. Muñoz, Biel; Al: Matus, Munita (sr) [unificación de jurisprudencia laboral].

Arenas Farías, Ignacio con Municipalidad de Molina (2019): CS, 2 enero 2019 (Rol No 22890-2018), $4^{\text {a }}$ Sala. M: Chevesich (d), A. Muñoz, Biel; Al: Matus, Munita (sr) [unificación de jurisprudencia laboral].

Rodríguez Quenlo, Valeria con Municipalidad de Molina (2019): CS, 3 enero 2019 (Rol No 23143-2018), $4^{\text {a }}$ Sala. M: Blanco, Chevesich (d), A. Muñoz; Al: Quintanilla, Pallavicini (sr) [unificación de jurisprudencia laboral].

Garcés Fernández, Luis con Municipalidad de San Miguel (2019): CS, 3 enero 2019 (Rol Nº 20289-2018), $4^{a}$ Sala. M: Blanco, Chevesich, A. Muñoz; Al: Abuauad, Pallavicini (sr) [unificación de jurisprudencia laboral].

Muñoz Veliz, Karina con Municipalidad de Coquimbo (2019): CS, 3 enero 2019 (Rol No 14755-2018), $4^{\text {a }}$ Sala. M: Fuentes, Blanco, Chevesich; Al: Munita, Gajardo (sr) [unificación de jurisprudencia laboral].

Rojas Ramírez, Miguel con Municipalidad de Valparaíso (2019): Corte Suprema, 7 enero 2019 (Rol No 2333-2018), Cuarta Sala. Ministros: Blanco, Chevesich, A. Muñoz; Abogados integrantes: Abuauad, Pallavicini (sr) [unificación de jurisprudencia laboral].

Delgado Pino, Daniel con Municipalidad de La Cisterna (2019): CS, 7 enero 2019 (Rol No 18936-2018), $4^{a}$ Sala. M: Blanco, Chevesich, A. Muñoz; Al: Abuauad, Pallavicini (sr) [unificación de jurisprudencia laboral].

Lin Muñoz, Tai I con Secretaría Regional Ministerial de la Vivienda y Urbanismo (2019): CS,

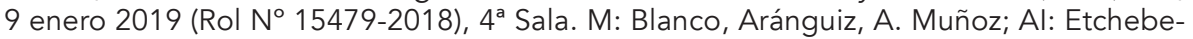
rry, De la Maza (sr) [unificación de jurisprudencia laboral].

Risco Saldivia, Sandra con Municipalidad de Valparaíso (2019): CS, 9 enero 2019 (Rol $N^{\circ}$ 12661-2018), 4a Sala. M: Blanco, Chevesich, A. Muñoz, Vivanco, Prado (sr) [unificación de jurisprudencia laboral].

Román Gutiérrez, Lía con Municipalidad de Maipú (2019): CS, 9 enero 2019 (Rol No 25061 2018), 4a Sala. M: Blanco, Chevesich (d), A. Muñoz; Al: Etcheberry, Gajardo (sr) [unificación de jurisprudencia laboral]. 
Martínez González, Diego con Municipalidad de Maipú (2019): CS, 9 enero 2019 (Rol No 19163-2018), $4^{\text {a }}$ Sala. M: Fuentes, Blanco, A. Muñoz; Al: Etcheberry, De la Maza [unificación de jurisprudencia laboral].

Requena Donoso, Fernando con Municipalidad de Cerrillos (2019): CS, 16 enero 2019 (Rol No 18701-2018), $4^{\text {a }}$ Sala. M: Blanco, Chevesich (d), A. Muñoz; Al: Quintanilla, Pallavicini [unificación de jurisprudencia laboral].

Roa Sanhueza, Marcelo con Municipalidad de Huechuraba (2019): CS, 17 enero 2019 (Rol N 28266-2018), 4 a Sala. M: Chevesich (d), A. Muñoz, Gómez; Al: Quintanilla, Abuauad (sr) [unificación de jurisprudencia laboral].

Montecinos Acaricia, Israel con Municipalidad de Vilcún (2019): CS, 17 enero 2019 (Rol N 26509-2018), 4a Sala. M: Chevesich (d), A. Muñoz, Gómez; Al: Quintanilla, Abuauad (sr) [unificaciòn de jurisprudencia laboral].

Tobar Aedo, Andrés con Municipalidad de Huechuraba (2019): CS, 17 enero 2019 (Rol N²5059-2018), 4a Sala. M: Chevesich (d), A. Muñoz, Gómez; Al: Quintanilla, Abuauad (sr) [unificación de jurisprudencia laboral].

Pando Monarde, Ángel con Municipalidad de Quilicura (2019): CS, 22 enero 2019 (Rol $N^{\circ}$ 25185-2018), $4^{a}$ Sala. M: Blanco, A. Muñoz, Biel; Al: Quintanilla, Abuauad (sr) [unificación de jurisprudencia laboral].

Trujillo Osorio, Rafael con Municipalidad de Melipilla (2019): CS, 31 enero 2019 (Rol No 8448-2018), 4a Sala. M: Chevesich (d), A. Muñoz, Gómez; Al: Abuauad, Pallavicini (sr) [unificación de jurisprudencia laboral].

Alvarado Bustos, Natalia con Municipalidad de Melipilla (2019): CS, 31 enero 2019 (Rol N 8447-2018), 4ª Sala. M: Chevesich (d), A. Muñoz, Gómez; Al: Abuauad, Pallavicini (sr) [unificación de jurisprudencia laboral].

Urrutia Martínez, Paola Carolina con Municipalidad de Valparaíso (2019): CS, 20 febrero

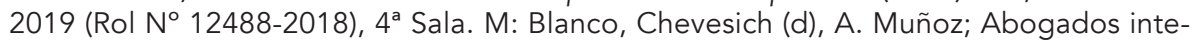
grantes: Etcheberry, Abuauad (sr) [unificación de jurisprudencia laboral].

Gómez Monroy, Ricardo con Municipalidad de Maipú (2019): CS, 21 febrero 2019 (Rol $N^{\circ}$ 23208-2018), $4^{a}$ Sala. M: Blanco, Chevesich, A. Muñoz; Abogados integrantes: Etcheberry, Abuauad (sr) [unificación de jurisprudencia laboral].

Mora Rivas, Rocío con Municipalidad de Cobquecura (2019): CS, 26 febrero 2019 (Rol $N^{\circ}$ 26271-2018), $4^{a}$ Sala. M: Chevesich, A. Muñoz, Meins; Al: Etcheberry, Barra (sr) [unificación de jurisprudencia laboral].

Cortés Cerda, Rodrigo con Municipalidad de Las Condes (2019): CS, 27 febrero 2019 (Rol $N^{\circ}$ 18695-2018), $4^{a}$ Sala. M: Blanco, Chevesich, A. Muñoz; Al: Quintanilla, Munita (sr) [unificación de jurisprudencia laboral].

Cáceres Cáceres, Jocelyn con Municipalidad de Buin (2019): CS, 4 marzo 2019 (Rol $N^{\circ}$ 25079-2018), 4a Sala. M: Chevesich (d), A. Muñoz, Gómez; Al: Matus, Gajardo (sr) [unificación de jurisprudencia laboral].

Báez Simpertigue, Alejandra con Municipalidad de Talcahuano (2019): CS, 4 marzo 2019 (Rol N² 23116-2018), $4^{\text {a }}$ Sala. M: Chevesich, A. Muñoz, Gómez; Al: Matus, Gajardo (sr) [unificación de jurisprudencia laboral].

Soto Charme, Paulina y otra con Municipalidad de La Pintana (2019): CS, 5 marzo 2019 (Rol No 6583-2018), 4 a Sala. M: Blanco (d), A. Muñoz, Vivanco; Al: Etcheberry, De la Maza (sr) [unificación de jurisprudencia laboral].

Barrera Valdés, Felipe con Municipalidad de Maipú (2019): CS, 14 marzo 2019 (Rol $N^{\circ}$ 22881-2018), $4^{a}$ Sala. M: Blanco, A. Muñoz, Biel; Al: Quintanilla, Abuauad (sr) [unificación de jurisprudencia laboral].

Quinchel Díaz, Luis con Municipalidad de Maipú (2019): CS, 25 marzo 2019 (Rol N 41422018), $4^{a}$ Sala. M: Chevesich, A. Muñoz, Gómez; Al: Etcheberry, Munita (sr) [unificación de jurisprudencia laboral].

Acevedo Parra, Carol con Instituto Nacional de Estadísticas (2019): CS, 11 abril 2019 (Rol No 3940-2019) M: Blanco, A. Muñoz, M. Silva; Al: Abuauad, De la Maza (sr) [unificación de jurisprudencia laboral]. 
Sandoval Garrido, Aldo y otro con Municipalidad de Pinto (2019): CS, 15 abril 2019 (Rol NN 16650-2018), 4a Sala. M: Blanco, Aránguiz (d), A. Muñoz; Al: Quintanilla, Etcheberry (sr) [unificación de jurisprudencia laboral].

Zorricueta Miranda, Angélica María con Municipalidad de La Reina (2019): CS, 29 abril 2019 (Rol N 31236-2018), 4a Sala. M: Blanco, A. Muñoz (d), M. Silva; Al: Etcheberry (d), Abuauad (sr) [unificación de jurisprudencia laboral].

Ramos Miranda, Ximena con Municipalidad de Coquimbo (2019): CS, 29 abril 2019 (Rol $N^{\circ}$ 25069-2018), $4^{a}$ Sala. M: Blanco, A. Muñoz, M. Silva (p); Al: Etcheberry, Abuauad (sr) [unificación de jurisprudencia laboral].

Medina Pérez, Mariela Paulina con Agencia de Calidad de la Educación (2019): CS, 29 abril 2019 (Rol N 31696-2018), $4^{\text {a }}$ Sala. M: Künsemüller, Blanco, A. Muñoz, M. Silva; Al: Munita (sr) [unificación de jurisprudencia laboral].

Morales Onell, Melany Andrea con Gobierno Regional de Arica y Parinacota (2019): CS, 2 mayo 2019 (Rol No 29515-2018), 4a Sala. M: Blanco, A. Muñoz, M. Silva; Al: Etcheberry, De la Maza (sr) [unificación de jurisprudencia laboral].

Elso Sandoval, Jorge con Municipalidad de Talcahuano (2019): CS, 6 mayo 2019 (Rol No 31611-2018), 4a Sala. M: Blanco, A. Muñoz, M. Silva; Al: Abuauad, De la Maza (sr) [unificación de jurisprudencia laboral].

Montecino Venegas, Cristhoper con Municipalidad de Florida (2019): CS, 6 mayo 2019 (Rol $N^{\circ}$ 14764-2018), $4^{\text {a }}$ Sala. M: Blanco, Chevesich (d), A. Muñoz; Al: Etcheberry, Munita (sr) [unificación de jurisprudencia laboral].

Toncio Morales, Karen con Municipalidad de Rengo (2019): CS, 15 mayo 2019 (Rol No 28229-2018), $4^{\text {a }}$ Sala. M: Blanco, Chevesich (d), A. Muñoz, M. Silva; Al: Etcheberry (sr) [unificación de jurisprudencia laboral].

Cerón Acevedo, Carolina con Instituto Nacional de Estadísticas (2019): CS, 20 mayo 2019 (Rol No 32696-2018), $4^{\text {a }}$ Sala. M: Blanco, Chevesich, A. Muñoz, M. Silva; Al: De la Maza (sr) [unificación de jurisprudencia laboral].

Soto Santibáñez, Carlos con Municipalidad de Rengo (2019): CS, 23 mayo 2019 (Rol $N^{\circ}$ 29867-2018), $4^{a}$ Sala. M: Blanco, A. Muñoz, M. Silva; Al: Quintanilla, Etcheberry (sr) [unificación de jurisprudencia laboral].

Domínguez Ramírez, Fabián con Municipalidad de Hualpén (2019): CS, 11 junio 2019 (Rol

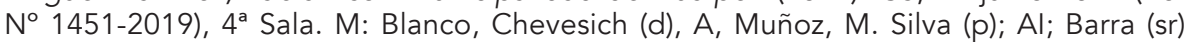
[unificación de jurisprudencia laboral].

Carrasco Moreno, Minda con Municipalidad de Melipilla (2019): CS, 17 junio 2019 (Rol $N^{\circ}$ 3679-2019), $4^{a}$ Sala. M: Blanco, Chevesich (d), A. Muñoz, M. Silva (p); Al: Barra (sr) [unificación de jurisprudencia laboral].

Zúñiga Soto, Sergio con Municipalidad de Maipú (2019): CS, 20 junio 2016 (Rol № 250602018), $4^{a}$ Sala. M: Blanco, A. Muñoz, M. Silva; Al: Etcheberry, De la Maza (sr) [unificación de jurisprudencia laboral].

Del Solar Mattehensohn, Luis con Municipalidad de Maipú (2019): CS, 24 junio 2019 (Rol No 4440-2019), 4a Sala. M: Blanco, Chevesich (d), A. Muñoz; Al: Etcheberry, Barra (sr) [unificación de jurisprudencia laboral].

Salinas Astudillo, Karen con Servicio Electoral (2019): CS, 26 junio 2019 (Rol № 3502-2019), $4^{a}$ Sala. M: Blanco, A. Muñoz, M. Silva; Al: Etcheberry, De la Maza (sr) [unificación de jurisprudencia].

Sierra D'Orival, Álvaro Patricio con Instituto Nacional de Estadísticas (2019): CS, 1 julio 2019 (Rol No 4490-2019), 4a Sala. M: Blanco, A. Muñoz, Prado (p); Al: M. Silva (p), Etcheberry (sr) [unificación de jurisprudencia laboral].

Aguilera Castex, Flaviano con Municipalidad de Illapel (2019): CS, 3 julio 2019 (Rol $N^{\circ}$ 2186-2019), $4^{a}$ Sala. M: Blanco, A. Muñoz, M. Silva; Al: Etcheberry, Barra (sr) [unificación de jurisprudencia laboral].

Muñoz Arrué, Marisol del Carmen con Municipalidad de Maipú (2019): CS, 3 julio 2019 (Rol $N^{\circ}$ 30627-2018), 4a Sala. M: Blanco, A. Muñoz, M. Silva (p); Al: Etcheberry, Barra (sr) [unificación de jurisprudencia laboral]. 
Cheuquelaf Morales, Marcia Catalina con Instituto Nacional de Estadísticas (2019): CS, 3 julio 2019 (Rol No 5803-2019), 4ª Sala. M: Blanco, Chevesich (d), A. Muñoz; Al: Etcheberry, Munita (sr) [unificación de jurisprudencia laboral].

Ramírez Salinas, María Mercedes con Instituto Nacional de Estadísticas (2019): CS, 18 julio 2019 (Rol N 4511-2019), 4a Sala. M: Blanco, A. Muñoz (p), Prado (p), M. Silva (p); Al: Etcheberry (sr) [unificación de jurisprudencia laboral].

Romero Pastene, María Ena con Municipalidad de Maipú (2019): CS, 18 julio 2019 (Rol No 4510-2019), 4 Sala. M: Blanco, A. Muñoz, M. Silva (p); Al: Etcheberry, Abuauad (sr) [unificación de jurisprudencia laboral].

Palma Garrido, María Cristina con Municipalidad de Maipú (2019): CS, 18 julio 2019 (Rol No 4457-2019), 4 Sala. M: Blanco, A. Muñoz, M. Silva (p); Al: Etcheberry, Abuauad (sr) [unificación de jurisprudencia laboral].

Riquelme Fuentealba, Marlys con Municipalidad de Peñalolén (2019): CS, 18 julio 2019 (Rol No 5800-2019), 4a Sala. M: Blanco, A. Muñoz, M. Silva; Al: Etcheberry, Abuauad (sr) [unificación de jurisprudencia laboral].

Toledo González, Gabriel Adrián con Corporación Nacional de Desarrollo Indígena (2019): CS, 25 julio 2019 (Rol No 4907-2019), 4ª Sala. M: Blanco, A. Muñoz, M. Silva; Al: Etcheberry, De la Maza (sr) [unificación de jurisprudencia laboral].

Courten Sepúlveda, Pablo César con Instituto Nacional de Estadísticas (2019): CS, 14 agosto 2019 (Rol N 4515-2019), 4ª Sala. M: Cisternas, Blanco, Chevesich (d); Al: Munita, Barra (sr) [unificación de jurisprudencia laboral].

Elgueta Venegas, Lorena Alejandra con Municipalidad de Providencia (2019): CS, 14 agosto 2019 (Rol N 9784-2019), 4ª Sala. M: Chevesich (d), A. Muñoz, M. Silva, González; Al: De la Maza (sr) [unificación de jurisprudencia laboral].

Vargas Riquelme, Jorge Andrés con Municipalidad de Calbuco (2019): CS, 14 agosto 2019 (Rol No 11993-2019), 4ª Sala. M: Chevesich (d), A. Muñoz, M. Silva (p), González; Al: De la Maza (sr) [unificación de jurisprudencia laboral].

Zamorano Mendoza, Moisés Aarón con Fisco de Chile (2019): CS, 20 agosto 2019 (Rol No 4611-2019), 4ª Sala. M: Cisternas, Blanco, Chevesich (d); Al: Munita, Barra (sr) [unificación de jurisprudencia laboral].

Gárate Castro, Samuel Esteban con Corporación Municipal Conchalí de Educación, Salud y Atención a Menores (2019): CS, 1 octubre 2019 (Rol N 4496-2019), 4a Sala. M: A. Muñoz, M. Silva (p), Repetto; Al: Barra, De la Maza (sr) [unificación de jurisprudencia laboral].

Ibarra Rojas, Hans Carlos con Servicio Agrícola y Ganadero (2019): CS, 7 octubre 2019 (Rol No 3947-2019), 4ª Sala. M: A. Muñoz, M. Silva (p), González; Al: Quintanilla, Etcheberry (sr) [unificación de jurisprudencia laboral].

Arancibia Castro, Fabián Octavio con Municipalidad de Sagrada Familia y del Instituto de Desarrollo Agropecuario (2019): CS, 11 octubre 2019 (Rol N 8272-2018), 4ª Sala. M: A. Muñoz, M. Silva, Repetto; Al: Pallavicini, De la Maza (sr) [unificación de jurisprudencia laboral].

Silva Ballesteros, Juana del Carmen con Municipalidad de Puerto Montt (2019): CS, 14 octubre 2019 (Rol N²39-2018), 4ª Sala. M: A. Muñoz, Prado, Repetto; Al: Etcheberry, De la Maza (sr) [unificación de jurisprudencia laboral].

Mansilla Silva, Luis Rodolfo con Fisco de Chile (2019): CS, 23 octubre 2019 (Rol N 315692018), $4^{a}$ Sala. M: Brito, Chevesich (d), A. Muñoz; Al: Pallavicini, De la Maza (sr) [unificación de jurisprudencia laboral].

Aguirre Maureira, Pier con Municipalidad de Melipilla (2019): CS, 25 octubre 2019 (Rol No 12653-2019), $4^{\text {a }}$ Sala. M: Brito, Chevesich (d), A. Muñoz; Al: Pallavicini, De la Maza (sr) [unificación de jurisprudencia laboral].

Porras Monterrey, Pablo Alfonso con Corporación Nacional de Desarrollo Indígena (2019): CS, 5 noviembre 2019 (Rol No 12191-2019), 4ª Sala. M: Brito, Chevesich (d), A. Muñoz; Al: Pallavicini, De la Maza (sr) [unificación de jurisprudencia laboral]. 
Delteil Muñoz, Philippe con Servicio de Salud Metropolitano Sur Oriente (2019): CS, 5 noviembre 2019 (Rol No 11419-2019), 4a Sala. M: Chevesich (d), A. Muñoz, Prado; Al: Etcheberry, Barra (sr) [unificación de jurisprudencia laboral].

Aguilera Aguilera, Marjorie Evelyn con Instituto Nacional de Estadísticas (2019): CS, 11 noviembre 2019 (Rol No 13786-2019), 4ª Sala. M: Chevesich (d), A. Muñoz, Repetto; Al: Abuauad, De la Maza (sr) [unificación de jurisprudencia laboral].

Muñoz Monardes, Paula y otros con Fondo Solidario e Inversión Social (2019): CS, 11 noviembre 2019 (Rol No 11239-2019), 4a Sala. M: Chevesich (d), A. Muñoz, Repetto; Al: Abuauad, De la Maza (sr) [unificación de jurisprudencia laboral].

Sánchez Díaz, Manuel con Instituto Nacional de Estadísticas (2019): CS, 25 noviembre 2019 (Rol No 13336-2019), 4a Sala. M: Chevesich (d), A. Muñoz, M. Silva (p), Repetto; Al: Barra (sr) [unificación de jurisprudencia laboral].

Faúndez Saavedra, Clara con Municipalidad de Maipú (2019): CS, 25 noviembre 2019 (Rol No 11215-2019), $4^{\text {a }}$ Sala. M: Chevesich (d), A. Muñoz, M. Silva (p), Repetto; Al: Barra (sr) [unificación de jurisprudencia laboral].

Canales Huerta, Juan José con Fisco de Chile (2019): CS, 28 noviembre 2019 (Rol No 15405-2019), $4^{\text {a }}$ Sala. M: M. Silva (p), Repetto, Mera; Al: Lagos, Gajardo (sr) [unificación de jurisprudencia laboral].

García Caro, Miguel Ángel con Servicio de Gobierno Regional de Magallanes y Antártica Chilena (2019): CS, 29 noviembre 2019 (Rol No 13367-2019), 4ª Sala. M: A. Muñoz, Prado, M. Silva (d), Repetto, González (d) (sr) [unificación de jurisprudencia].

\section{Término anticipado de empleos a contrata [98 casos]}

Araneda Neira, Marcia con Gobierno Regional de la Región del Biobío (2018): CS, 20 diciembre 2018 (Rol No 24943-2018), 3a Sala. M: Sandoval, Vivanco (d), Biel (r); Al; Pallavicini, Gajardo (d) [protección].

Fuentes Ortiz, Eduardo y otros con Subsecretaría de Vivienda y Urbanismo (2018): CS, 20 diciembre 2018 (Rol No 25029-2018), $3^{\text {a }}$ Sala. M: Sandoval, Vivanco (d), Biel (r); Al: PaIlavicini, Gajardo (p) [protección].

Jaquieh Nieto, Araceli con Instituto Nacional de Estadísticas (2018): CS, 20 diciembre 2018 (Rol No 22061-2018), 3a Sala. M: Sandoval, Vivanco (d), Biel (r); Al: Pallavicini, Gajardo (p) [protección].

Elgueta Lineros, Luis con Subsecretaría del Ministerio del Interior (2019): CS, 23 enero 2019 (Rol No 26439-2018), 3a Sala. M: Egnem, Aránguiz, A. Muñoz; Al: Matus, Pallavicini (r) [protección].

Aedo Álvarez, Karina con Gobernación Provincial de San Antonio (2019): CS, 24 enero 2019 (Rol No 24812-2018), $3^{a}$ Sala. M: Sandoval, Prado, Vivanco; Al: Etcheberry, Munita (r) [protección].

Escobar Villagra, María con Servicio de Vivienda y Urbanización (2019): CS, 28 enero 2019 (Rol No 28238-2018), $3^{\text {a }}$ Sala. M: S. Muñoz, Sandoval (r) (d), Prado (p), Vivanco; Al: Munita [protección].

Muñoz Lira, Felipe con Ministerio de Obras Públicas (2019): CS, 28 enero 2019 (Rol $N^{\circ}$ 28466-2018), $3^{a}$ Sala. M: S. Muñoz, Sandoval (r) (d), Prado (p), Vivanco; Al: Munita [protección].

Cea Mora, Roberto con Subsecretaría del Ministerio del Interior (2019): CS, 19 febrero 2019 (Rol N² 29608-2018), $3^{\text {a }}$ Sala. M: Aránguiz, S. Muñoz (p), Prado, Sandoval (d) (r), Vivanco [protección].

Colihuil Binimelis, José con Ministerio del Interior y Seguridad Pública (2019): CS, 19 febrero 2019 (Rol No 29477-2018), $3^{a}$ Sala. M: S. Muñoz (r), Prado, Vivanco; Al: Pierry (d), Pallavicini (d) [protección].

Mundaca Mundaca, Edmundo German con Subsecretaría del Interior (2019): CS, 21 febrero 2019 (Rol N² 29441-2018), $3^{\text {a }}$ Sala. M: Aránguiz (r), S. Muñoz (p), Sandoval (d), Prado, Vivanco [protección]. 
Céspedes Silva, Deysy con Subsecretaría de Transportes (2019): CS, 21 febrero 2019 (Rol No 29332-2018), $3^{a}$ Sala. M: S. Muñoz, Sandoval (d), Aránguiz, Prado (r), Vivanco (d) [protección].

Astorga Santoro, Maiten con Ministerio de Obras Públicas (2019): CS, 27 febrero 2019 (Rol $N^{\circ}$ 28470-2018), $3^{a}$ Sala. M: S. Muñoz (p), Sandoval (d) (r), Prado (p), Vivanco; Al: Munita [protección].

López Palma, Felipe con Dirección de Obras Hidráulicas (2019): CS, 27 febrero 2019 (Rol $N^{\circ}$ 28328-2018), $3^{a}$ Sala. M: S. Muñoz (d), Sandoval, Aránguiz, Prado, Vivanco (r) (d) [protección].

Orellana Trincado, Oscar con Dirección General de Crédito Prendario (2019): CS, 28 febrero 2019 (Rol N² 2552-2019), 3a Sala. M: S. Muñoz (d), Blanco, Vivanco, Biel, J. Muñoz (r) [protección].

Meléndez Jiménez, Rosa con Agencia Nacional de Inteligencia (2019): CS, 11 marzo 2019 (Rol No 22174-2018), $3^{\text {a }}$ Sala. M: S. Muñoz (d), Prado (d) (r), Sandoval; Al: De la Maza, Pierry [protección].

Durán Bravo, Maribel con Servicio de Registro Civil e Identificación (2019): CS, 11 marzo 2019 (Rol N²34-2019), $3^{a}$ Sala. M: S. Muñoz (d), Sandoval, Vivanco (d); Al: Quintanilla (r), Pierry (p) [protección].

Arrepol Barra, Marcelo con Subsecretaría del Interior (2019): CS, 11 marzo 2019 (Rol No 241-2019), $3^{\text {a }}$ Sala. M: S. Muñoz (d), Sandoval, Vivanco (d); Al: Pierry, Quintanilla (r) [protección].

Mora Fuentes, Luis Alberto con Instituto de Desarrollo Agropecuario (2019): CS, 12 marzo 2019 (Rol N²700-2019), $3^{a}$ Sala. M: Biel, Blanco (r), S. Muñoz, J. Muñoz, Vivanco [protección].

Hohmann Toledo, Enrique Alberto con Secretaría Regional Ministerial de Educación Los Lagos (2019): CS, 12 marzo 2019 (Rol No 32723-2018), 3a Sala. M: Aránguiz (d), S. Muñoz (p), Prado, Sandoval (d); Al: Gómez (r) [protección].

Roa Cerda, Cristhian Manuel con Dirección de Obras Hidráulicas (2019): CS, 12 marzo 2019 (Rol No 1319-2019), $3^{\text {a }}$ Sala. M: Biel, Blanco, J. Muñoz (r), Vivanco; Al: Pallavicini [protección].

Fernández Carrera, Karina Angélica con Subsecretaría de Evaluación Social (2019): CS, 13 marzo 2019 (Rol No 29757-2018), 3ª Sala. M: Prado, Sandoval (d), Vivanco; Al: Pierry (d), Quintanilla (r) [protección].

Segura Domínguez, Renato Arturo con Dirección General de Relaciones Económicas Internacionales (2019): CS, 14 marzo 2019 (Rol No 24594-2018), 3a Sala. M: Sandoval, Prado, Vivanco; Al: Munita (r), Pierry (p) [protección].

Navarrrete García, Héctor con Superintendencia de Educación (2019): CS, 19 marzo 2019 (Rol No 5530-2019), $3^{a}$ Sala. M: S. Muñoz (d), Sandoval, Vivanco; Al: Quintanilla, Pallavicini (sr) [protección].

Saralegui Martínez, Hermes con Servicio de Salud Osorno (2019): CS, 19 marzo 2019 (Rol No 5526-2019), $3^{\text {a }}$ Sala. M: S. Muñoz (d), Sandoval, Vivanco; Al: Quintanilla, Pallavicini (sr) [protección].

Servicio Nacional del Adulto Mayor con Villagra Rojas, Flabio Miguel (2019): CS, 19 marzo 2019 (Rol N² 28121-2018), $3^{\text {a }}$ Sala. M: S. Muñoz (p), Sandoval (d) (r), Aránguiz, Prado; Al: Barra [protección].

Molina Millán, Jorge con Servicio de Salud O'Higgins (2019): CS, 21 marzo 2019 (Rol $N^{\circ}$ 2551-2019), $3^{a}$ Sala. M: S. Muñoz (d), Blanco, Prado (r), Vivanco, Biel [protección].

Muñoz González, Jaime Arturo con Servicio de Vivienda y Urbanismo de la Región del Maule (2019): CS, 21 marzo 2019 (Rol No 22181-2018), 3a Sala. M: Sandoval (d) (r), Prado, Vivanco; Al: Etcheberry, Munita [protección].

Rojas Luarte, Rodolfo con Subsecretaría de Vivienda y Urbanismo (2019): CS, 21 marzo 2019 (Rol N²6198-2018), $3^{a}$ Sala. M: Egnem (p), Aránguiz (d), A. Muñoz (p); Al: Matus, Pallavicini (r) [protección]. 
Ríos López, Cristián con Fiscalía Nacional del Ministerio de Obras Públicas (2019): CS, 21 marzo 2019 (Rol N 33013-2018), 3ª Sala. M: S. Muñoz (d) (r), Sandoval (p), Aranguiz, Prado; Al: Gómez [protección].

Pojomovsky De la Carrera, Valentina con Instituto Nacional de la Juventud (2019): CS, 25 marzo 2019 (Rol N²3027-2018), 3ª Sala. M: S. Muñoz (d), Sandoval (r), Aránguiz, Prado, Vivanco [protección].

Quiero Aguirre, Francisco con Fondo de Solidaridad e Inversión Social (2019): CS, 25 marzo 2019 (Rol N 32983-2018), 3ª Sala. M: S. Muñoz (d), Sandoval (p), Aránguiz, Prado; Al: Gómez (d) (r) [protección].

Servicio de Vivienda y Urbanismo con Torres Pastene, Dayana (2019): CS, 26 marzo 2019 (Rol No 26441-2018), $3^{a}$ Sala. M: S. Muñoz (p), Sandoval (d), Prado, Vivanco (r); Al: Munita [protección].

Sepúlveda Cortés, Galo con Gendarmería de Chile (2019): CS, 26 marzo 2019 (Rol N²6304-2018), $3^{a}$ Sala. M: S. Muñoz, Sandoval (d), Prado, Vivanco (r); Al: Munita [protección].

Carrasco González, Fabiola con Servicio de Vivienda y Urbanismo de la Región de la Araucanía (2019): CS, 26 marzo 2019 (Rol N²6437-2018), 3a Sala. M: S. Muñoz (p), Sandoval (d), Prado, Vivanco (r); Al: Munita [protección].

Díaz Núñez, Yasmín con Ministerio de Desarrollo Social (2019): CS, 1 abril 2019 (Rol $N^{\circ}$ 2062-2019), $3^{a}$ Sala. M: Biel, Blanco (d), J. Muñoz, Vivanco (r); Pallavicini [protección].

Silva Arancibia, Michael con Servicio Nacional de Turismo (2019): CS, 1 abril 2019 (Rol $N^{\circ}$ 3912-2019), $3^{a}$ Sala. M: S. Muñoz (d), Sandoval, Blanco (r), Prado, Vivanco [protección].

Sepúlveda Sandoval, Marlies con Ministerio de Salud (2019): CS, 1 abril 2019 (Rol N 68082019), $3^{a}$ Sala. M: S. Muñoz (d), Sandoval, Aránguiz (d), Prado, Vivanco (sr) [protección].

Espinoza Mercado, Marco con Gobierno Regional de Arica y Parinacota (2019): CS, 1 abril 2019 (Rol N² 2325-2019), $3^{a}$ Sala. M: Biel, Blanco (d), J. Muñoz, Vivanco (r); Al: Pallavicini [protección].

Escobar Acosta, Angel con Servicio de Vivienda y Urbanismo Región Arica y Parinacota (2019): CS, 1 abril 2019 (Rol N²513-2019), 3a Sala. M: S. Muñoz (d), Blanco (d), Vivanco, Biel, J. Muñoz (r) [protección].

Cuevas Cuevas, Andrés con Junta Nacional de Jardines Infantiles (2019): CS, 1 abril 2019 (Rol N 7229-2019), 3ª Sala. M: S. Muñoz (d), Sandoval, Aránguiz (d), Prado, Vivanco [protección].

Donner Valerio, Claudia Gabriela con Ministerio de Obras Públicas (2019): CS, 8 abril 2019 (Rol No 3641-2019), $3^{a}$ Sala. M: S. Muñoz (p), Sandoval, Blanco (r), Prado, Vivanco [protección].

Wiederhold Castro, Gabriela Andrea con Servicio de Salud Osorno (2019): CS, 10 abril 2019 (Rol N 5203-2019), 3a Sala. M: S. Muñoz (d), Sandoval (r), Blanco, Prado, Vivanco [protección].

Almonacid Soto, Guillermina con Servicio Nacional de Turismo (2019): CS, 22 abril 2019 (Rol No 247-2019), $3^{a}$ Sala. M: S. Muñoz (d), Sandoval, Vivanco; Al: Etcheberry, Pierry (r) [protección].

Torres González, Paola Soledad con Instituto de Desarrollo Agropecuario (2019): CS, 22 abril 2019 (Rol N 5556-2019), 3a Sala. M: S. Muñoz (d) (r), Sandoval, Vivanco; Al: Quintanilla, Pallavicini [protección].

Pinilla Altamirano, Luis con Fondo de Solidaridad e Inversión Social (2019): CS, 23 abril 2019 (Rol N²762-2019), $3^{a}$ Sala. M: Blanco, S. Muñoz (p), Prado, Vivanco (r); Al: Munita [protección].

Vargas Arriagada, María con Servicio de Vivienda y Urbanismo de la Región de la Araucanía (2019): CS, 24 abril 2019 (Rol N 33017-2018), 3a Sala. M: S. Muñoz (p), Sandoval (d), Vivanco (r); Al: Etcheberry, Pallavicini (d) [protección]. 
Briones Guerrero, María Angélica con Subsecretaría de Prevención del Delito (2019): CS, 29 abril 2019 (Rol N 6800-2019), 3ª Sala. M: Sandoval, Aránguiz (d), Vivanco; Al: Quintanilla (r), Munita [protección].

Muñoz Leiva, Daniela Francisca con Ministerio de Bienes Nacionales (2019): CS, 29 abril 2019 (Rol N 6781-2019), $3^{a}$ Sala. M: Sandoval, Aránguiz, Vivanco; Al: Quintanilla (r), Munita [protección].

Morales Correa, César con Ministerio de Salud (2019): CS, 8 mayo 2019 (Rol № 51682019), $3^{a}$ Sala. M: S. Muñoz (d), Sandoval, Blanco, Prado, Vivanco (r) [protección].

Ascencio Vidal, Miguel con Junta Nacional de Auxilio Escolar y Becas (2019): CS, 13 mayo 2019 (Rol No 4787-2019), $3^{a}$ Sala. M: S. Muñoz (r) (p), Sandoval, Prado (p), Vivanco; Al: Matus (p) [protección].

Ganga Urbina, Gloria con Ministerio de Obras Públicas (2019): CS, 14 mayo 2019 (Rol No 5895-2019), $3^{\text {a }}$ Sala. M: S. Muñoz, Sandoval (d), Prado, Vivanco (r); Al: Pallavicini (d) [protección].

Pavez Gómez, Myrna Astrid con Servicio Nacional de la Mujer y Equidad de Género (2019): CS, 14 mayo 2019 (Rol N 5733-2019), 3ª Sala. M: S. Muñoz, Sandoval (p), Prado, Vivanco (r); Al: Pallavicini (d) [protección].

Medel Retamal, Blanca con Servicio Nacional del Adulto Mayor (2019): CS, 15 mayo 2019 (Rol No 24719-2018), $3^{\text {a }}$ Sala. M: S. Muñoz (p), Sandoval (d), Prado (r), Vivanco; Al: Munita [protección].

Rodríguez Cárdenas, Claudia con Instituto de Desarrollo Agropecuario (2019): CS, 22 abril 2019 (Rol N 5557-2019), $3^{a}$ Sala. M: S. Muñoz (d) (r), Sandoval, Vivanco; Al: Quintanilla, Pallavicini [protección].

Barría Angulo, Bernardo René con Instituto Nacional de la Juventud (2019): CS, 27 mayo 2019 (Rol N 5906-2019), $3^{a}$ Sala. M: S. Muñoz (p), Prado (r), Sandoval, Vivanco; Al: PaIlavicini (d) [protección].

Instituto Nacional de Desarrollo Agropecuario con Cancino Cáceres, Eduardo Alberto

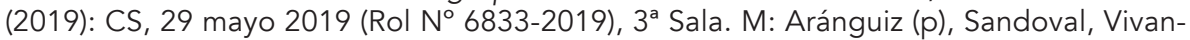
co; Al: Munita (r), Quintanilla [protección].

De la Fuente Alvarez, Ana María Isabel con Instituto Nacional de Desarrollo Agropecuario (2019): CS, 29 mayo 2019 (Rol No 6832-2019), $3^{a}$ Sala. M: Aránguiz (p), Sandoval (d), Vivanco; Al: Munita (r), Quintanilla [protección].

Arcos García, Paula Andrea con Junta Nacional de Auxilio Escolar y Becas (2019): CS, 3 junio 2019 (Rol No 5495-2019), 3a Sala. M: S. Muñoz (r), Prado, Sandoval (d); Al: Pierry, Etcheberry [protección].

Poblete Ferrer, Fernando con Junta Nacional de Auxilio Escolar y Becas (2019): CS, 3 junio 2019 (Rol N 5501-2019), $3^{a}$ Sala. M: S. Muñoz (r) (p), Sandoval (d), Prado; Al: Etcheberry, Pierry [protección].

Rojas Valdivia, Ariel Manuel con Junta Nacional de Auxilio Escolar y Becas (2019): CS, 3 junio 2019 (Rol No 5505-2019), 3a Sala. M: S. Muñoz (r) (p), Sandoval (d), Prado; Al: Pierry, Etcheberry [protección].

Rondón Humeres, Álvaro Tomás con Fondo de Solidaridad e Inversión Social (2019): CS, 3 junio 2019 (Rol N 5499-2019), 3a Sala. M: S. Muñoz (r) (p), Sandoval (d), Prado; Al: Pierry, Etcheberry [protección].

Barahona León, Fabián con Instituto de Desarrollo Agropecuario (2019): CS, 11 junio 2019 (Rol No 4803-2019), $3^{\text {a }}$ Sala. M: S. Muñoz (p) (r), Sandoval (d), Prado, Vivanco; Al: Matus (d) [protección].

Fuentes Reyes, Jorge con Fondo de Solidaridad e Inversión Social (2019): CS, 3 julio 2019 (Rol No 3404-2019), $3^{\text {a }}$ Sala. M: S. Muñoz (p), Sandoval (d), Blanco, Prado, Vivanco (r) [protección].

Peña Castro, Claudia con Servicio Nacional de Capacitación y Empleo (2019): CS, 9 julio 2019 (Rol No 7325-2019), $3^{a}$ Sala. M: S. Muñoz (r) (p), Sandoval (d), Prado, Vivanco; Al: Pallavicini (d) [protección]. 
Berger Salinas, Maureen con Junta Nacional de Auxilio Escolar y Becas (2019): CS, 24 julio 2019 (Rol No 16103-2019), 3ª Sala. M: Sandoval (d), Fuentes, J. Muñoz (r); Al: QuintaniIla, Munita [protección].

Sanhueza Córdova, Yasna con Ministerio de Las Culturas, Las Artes y El Patrimonio (2019): CS, 1 agosto 2019 (Rol No 1497-2019), 3a Sala. M: Blanco, Vivanco (p), Biel, J. Muñoz (r); Al: Barra [protección].

González Gelvez, Rita con Servicio Nacional para la Prevención y Rehabilitación del Consumo de Drogas y Alcohol (2019): CS, 11 septiembre 2019 (Rol N 12309-2019), $3^{\text {a }}$ Sala. M: Sandoval, Dahm, M. Silva; Al: Quintanilla, Pallavicini (r) (d) [protección].

Varela Campos, Daniela con Gobierno Regional Metropolitano de Santiago (2019): CS, 11 septiembre 2019 (Rol No 12294-2019), 3a Sala. M: Sandoval, Dahm, M. Silva (p); Al: Quintanilla, Pallavicini (d) (r) [protección].

Valenzuela Mejías, Pablo y otros con Instituto Nacional del Deporte (2019): CS, 24 septiembre 2019 (Rol N 11502-2019), 3ª Sala. M: S. Muñoz (p). Sandoval (d), Aránguiz (p), Prado (r), Vivanco [protección].

Seguel Jara, Ramón con Universidad de Santiago (2019): CS, 27 septiembre 2019 (Rol No 13307-2019), $3^{a}$ Sala. M: S. Muñoz (p), Sandoval (d), Vivanco; Al: Quintanilla (r), Etcheberry [protección].

Araya Valdés, Rubén con Servicio Nacional de Menores (2019): CS, 2 octubre 2019 (Rol $N^{\circ}$ 12536-2019), $3^{a}$ Sala. M: S. Muñoz (p), Sandoval (d), Vivanco; Al: Quintanilla (r), Etcheberry [protección].

Corveleyn Castro, Jorge con Municipalidad de Talca (2019): CS, 2 octubre 2019 (Rol $N^{\circ}$ 12588-2019), 3a Sala. M: S. Muñoz (p), Sandoval (d), Vivanco; Al: Quintanilla (r), Etcheberry [protección].

Lagos Parra, Cristián con Subsecretaría de Prevención del Delito (2019): CS, 17 octubre 2019 (Rol N 10692-2019), 3ª Sala. M: Aránguiz, Cisternas, Sandoval (d), Vivanco; Al: Quintanilla (r) [protección].

Ramos Navarrete, Gabriel con Servicio de Vivienda y Urbanismo Región de Valparaíso (2019): CS, 18 noviembre 2019 (Rol N²0916-2019), 3a Sala. M: S. Muñoz (p) (r), Sandoval (d), Aránguiz (p), Vivanco; Al: Pallavicini (d) [protección].

Castro Flores, María con Junta Nacional de Auxilio Escolar y Becas (2019): CS, 18 noviembre 2019 (Rol N²0737-2019), 3ª Sala. M: S. Muñoz (p) (r), Sandoval (d), Aránguiz (p), Vivanco; Al: Pallavicini (d) [protección].

Lamilla Canales, Zaida con Ministerio de Salud (2019): CS, 18 noviembre 2019 (Rol No 14948-2019), $3^{a}$ Sala. M: S. Muñoz (r), Sandoval (d), Vivanco, J. Muñoz; Al: Quintanilla (d) [protección].

Soto García, Patricia con Hospital de Ancud (2019): CS, 18 noviembre 2019 (Rol N²12612019), $3^{a}$ Sala. M: S. Muñoz (p) (r), Sandoval (d), Aránguiz (p), Vivanco; Al: Pallavicini (d) [casación].

Jadue Jadue, Solange con Dirección de Compras y Contratación Pública (2019): CS, 25 noviembre 2019 (Rol N 16914-2019), 3ª Sala. M: Sandoval (d), Fuentes, J. Muñoz (r); Al: Quintanilla, Munita [casación].

Torca Merino, Cristóbal Francisco con Gobierno Regional de la Araucanía (2019): CS, 3 diciembre 2019 (Rol No 33500-2019), 3ª Sala. M: S. Muñoz, Sandoval (d), Aránguiz, Vivanco; Al: Pallavicini (d) (sr) [protección].

Contreras Pardo, Yasna y Flores Chirre, Jaime con Corporación Administrativa del Poder Judicial (2019): CS, 4 diciembre 2019 (Rol N 15977-2019), 3a Sala. M: S. Muñoz (r), Sandoval (d), Aránguiz, Vivanco; Al: Pallavicini (d) [protección].

Pávez Carrasco, Haydee con Secretaría Regional Ministerial de Educación de la Región Metropolitana (2019): CS, 12 diciembre 2019 (Rol N 18445-2019), 3a Sala. M: S. Muñoz, Sandoval, J. Muñoz; Al: Abuauad (r), Pallavicini (d) [protección].

Zamorano Vargas, María Paz con Gobierno Regional Metropolitano de Santiago (2019): CS, 12 diciembre 2019 (Rol No 18440-2019), 3 Sala. M: S. Muñoz (d), Sandoval, J. Muñoz; Al: Abuauad (r), Pallavicini [protección]. 
Lagos Jara, Raquel Olivia con Gobierno Regional de la Araucanía (2019): CS, 12 diciembre 2019 (Rol N 17643-2019), $3^{a}$ Sala. M: S. Muñoz (d), Vivanco, J. Muñoz; Al: Pierry, Pallavicini (r) [protección].

Escobar Villagra, María con Servicio de Vivienda y Urbanización de la Región de la Araucanía (2019): CS, 12 diciembre 2019 (Rol No 17641-2019), 3ª Sala. M: S. Muñoz (d), Vivanco, J. Muñoz; Al: Pierry, Pallavicini (r) [protección].

Sepúlveda Maldonado, Juan Carlos con Servicio Nacional de Menores (2019): CS, 12 diciembre 2019 (Rol No 17619-2019), 3ª Sala. M: S. Muñoz, Vivanco, J. Muñoz; Al: Pierry (d), Pallavicini (r) (d) [protección].

Colihuil Binimelis, José con Subsecretaría de Desarrollo Regional y Administrativo (2019): CS, 12 diciembre 2019 (Rol N 17466-2019), 3ª Sala. M: S. Muñoz (d), Vivanco, J. Muñoz; Al: Pierry, Pallavicini (r) [protección].

García Lastarria, Miguel con Ministerio Secretaría General de Gobierno (2019): CS, 12 diciembre 2019 (Rol No 15478-2019), 3ª Sala. M: S. Muñoz, Vivanco, J. Muñoz; Al: Pierry (d), Pallavicini (d) (r) [protección].

Latin Quezada, Renán con Subsecretarría de Salud Pública (2019): CS, 12 diciembre 2019 (Rol No 15458-2019), $3^{\text {a }}$ Sala. M: S. Muñoz, Vivanco, J. Muñoz; Al: Pierry, Pallavicini (d) (r) [protección].

Simonet Romero, Romina Paz con Ministerio de la Mujer y Equidad de Género (2019): CS, 12 diciembre 2019 (Rol No 14812-2019), 3a Sala. M: S. Muñoz (p), Vivanco, J. Muñoz; Al: Pierry (d), Pallavicini (d) (r) [protección].

Espinoza Gavilán, Sergio con Subsecretaría de Desarrollo Regional y Administrativo (2019):

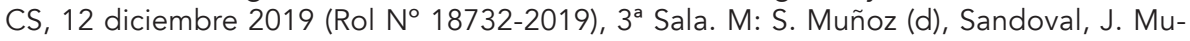
ñoz; Al: Abuauad (r), Pallavicini [protección].

González Nahum, Óscar con Servicio de Vivienda y Urbanización de la Región de la Araucanía (2019): CS, 12 diciembre 2019 (Rol No 18639-2019), 3a Sala. M: S. Muñoz (d), Sandoval, Vivanco; Al: Lagos (r), Barra [protección].

Valdebenito Solís, Cristian con Instituto de Desarrollo Agropecuario (2019): CS, 17 diciembre 2019 (Rol N²3210-2019), 3a Sala. M: S. Muñoz (d), Sandoval, Repettto (d); Al: Quintanilla, Pierry (r) [protección].

Álvarez Catalán, Claudio con Fondo de Solidaridad e Inversión Social (2019): CS, 17 diciembre 2019 (Rol No 23182-2019), $3^{\text {a }}$ Sala. M: S. Muñoz (d), Sandoval, Repettto (d); Al: Quintanilla, Pierry (r) [protección].

Nieto Navarrete, Gloria con Secretaría Regional Ministerial del Deporte de la Región de la Araucanía (2019): CS, 17 diciembre 2019 (Rol N²3058-2019), 3a Sala. M: S. Muñoz (d), Sandoval, Repettto (d); Al: Quintanilla, Pierry (r) [protección].

Torres Zalazar, Juan Manuel con Junta Nacional de Auxilio Escolar y Becas (2019): CS, 18 diciembre 2019 (Rol No 16982-2019), 3a Sala. M: S. Muñoz (p), Vivanco, J. Muñoz; Al: Pierry (d), Pallavicini (d) (r) [protección].

Muñoz Riveros, Héctor José con Gobierno Regional Metropolitano (2019): CS, 19 diciembre 2019 (Rol N 17756-2019), 3a Sala. M: S. Muñoz (p), Sandoval (d) (r), Vivanco, J. Muñoz; Al: Pallavicini [protección].

Martínez Rojas, Raúl Roger con Servicio Local de Educación de Puerto Cordillera (2019): CS, 19 diciembre 2019 (Rol No 17321-2019), 3ª Sala. M: S. Muñoz, Sandoval (d) (r), Vivanco; Al: Abuauad (r), Pierry (d) [protección].

Paredes Toledo, Marcela con Servicio Nacional de la Mujer y de la Equidad de Género (2019): CS, 19 diciembre 2019 (Rol No 15452-2019), 3a Sala. M: S. Muñoz, Sandoval (d), Aránguiz (r); Al: Lagos, Gómez [protección].

14. Desviación de poder en las desvinculaciones de funcionarios a contrata [12 casos]

Bustos Donoso, Juan con Subsecretaría del Ministerio de Minería (2019): CS, 20 febrero 2019 (Rol N² 29438-2018), 3a Sala. M: Aránguiz, S. Muñoz (r) (p), Prado, Sandoval, Vivanco [protección]. 
Mundaca Edmundo Germán con Subsecretaria del Interior (2019): CS, 21 febrero 2019 (Rol No 29441-2018), 3a Sala. M: Aránguiz (r), S. Muñoz (p), Prado, Sandoval (d), Vivanco [protección].

López Palma, Felipe con Dirección de Obras Hidráulicas (2019): CS, 27 febrero 2019 (Rol N ${ }^{\circ}$ 28328-2018), 3a Sala. M: Aránguiz, S. Muñoz (d), Prado, Sandoval, Vivanco (r) (d) [protección].

Meléndez Jiménez, Rosa con Agencia Nacional De Inteligencia (2019): CS, 11 marzo 2019 (Rol N²2174-2018), 3a Sala. M: S. Muñoz (d), Prado (r) (d), Sandoval; Al: De la Maza, Pierry [protección].

Condori Flores, Isabel con Subsecretaría del Interior (2019): CS, 8 abril 2019 (Rol No 36842019), 3a Sala. M: Blanco (r), S. Muñoz (d), Prado, Vivanco; Al: Munita [protección].

Aguilera Cuadra, Nevenka con Subsecretaria del Interior (2019): CS, 16 abril 2019 (Rol N 3683-2019), 3a. M: Blanco, S. Muñoz (d), Prado, Sandoval (r), Vivanco [protección].

Ganga Urbina, Gloria con Ministerio de Obras Públicas (2019): CS, 14 mayo 2019 (Rol Nº 5895-2019), 3a Sala. M: S. Muñoz, Sandoval (d), Prado, Vivanco (r); Al: Pallavicini (d) [protección].

Barría Angulo, Bernardo René con Instituto Nacional de la Juventud (2019): CS, 27 mayo 2019 (Rol N 5906-2019), 3a Sala. M: S. Muñoz (p), Sandoval (d), Vivanco, Prado (r); Al: Pallavicini (d) [protección].

Rondón Humeres, Álvaro con Fondo de Solidaridad e Inversión Social (2019): CS, 3 junio 2019 (Rol N 5499-2019), 3a Sala. M: S. Muñoz (r) (p), Sandoval (d), Prado; Al: Pierry, Etcheberry [protección].

Fuentes Reyes, Jorge con Fondo de Solidaridad e Inversión Social (2019): CS, 3 julio 2019 (Rol No 3404-2019), 3a Sala. M: S. Muñoz (p), Sandoval (d), Blanco, Prado, Vivanco (r) [protección].

Berger Salinas, Maureen con Junta Nacional de Auxilio Escolar y Becas (2019): CS, 24 julio 2019 (Rol No 16103-2019), 3a Sala. M: Sandoval (d), Fuentes, J. Muñoz (r); Al: QuintaniIla, Munita [protección].

Barrera Pedemonte, Loreto con Director del Trabajo y la Dirección del Trabajo (2019): CS, 24 octubre 2019 (Rol No 20959-2019), 3a Sala. M: Aránguiz, S. Muñoz, Sandoval (p), Vivanco; Al: Pallavicini (r) (p) [protección].

15. Recurso de protección como vía idónea en casos de desvinculación de funcionarios a contrata [98 casos]

Choque Pacaje, Aldo con Ministerio de Obras Públicas, Dirección General de Obras Públicas (2019): CS, 16 enero 2019 (Rol N 26575-2018), $3^{\text {a }}$ Sala. M: Sandoval, Fuentes (d), Prado (d); Al: Quintanilla (r), Pallavicini [protección].

Cancino Alvarez, Pablo con Instituto Nacional de la Juventud (2019): CS, 21 enero 2019 (Rol No 24783-2018), $3^{\text {a }}$ Sala. M: Prado, Sandoval (d), Vivanco; Al: Etcheberry, Munita (d) (r) [protección].

Oddo Kautz, Walter con Gobierno Regional Metropolitano de Santiago (2019): CS, 23 enero 2019 (Rol No 26445-2018), $3^{\text {a }}$ Sala. M: Aránguiz (d), Egnem, A. Muñoz; Al: Matus, Pallavicini (r) [protección].

Elgueta Lineros, Luis con Ministerio del Interior y Seguridad Pública (2019): CS, 23 enero 2019 (Rol N² 26439-2018), 3ª Sala. M: Aránguiz, Egnem, A. Muñoz; Al: Matus, Pallavicini (r) [protección].

Aedo Alvarez, Karina con Gobernación Provincial de San Antonio (2019): CS, 24 enero 2019 (Rol N² 24812-2018), 3a Sala. M: Sandoval, Prado, Vivanco; Al: Etcheberry, Munita (r) [protección].

Escobar Villagra, María con Servicio de Vivienda y Urbanización (2019): CS, 28 enero 2019 (Rol No 28238-2018), 3a Sala. M: S. Muñoz, Sandoval (r) (d), Prado (p), Vivanco; Al: Munita [protección].

Cea Mora, Roberto con Subsecretaría del Ministerio del Interior (2019): CS, 19 febrero 2019 (Rol N 29608-2018), $3^{a}$ Sala. M: Aránguiz, S. Muñoz (p), Prado, Sandoval (r) (d), Vivanco [protección]. 
Colihuil Binimelis, José con Ministerio del Interior y Seguridad Pública (2019): CS, 19 febrero 2019 (Rol N² 29477-2018), $3^{\text {a }}$ Sala. M: S. Muñoz (r), Prado, Vivanco; Al: Pierry (d), Pallavicini (d) [protección].

Bustos Donoso, Juan con Subsecretaría del Ministerio de Minería (2019): CS, 20 febrero 2019 (Rol N 29438-2018), $3^{a}$ Sala. M: S. Muñoz (r) (p), Sandoval, Aránguiz, Prado, Vivanco [protección].

Mundaca Edmundo, Germán con Subsecretaría del Interior (2019): CS, 21 febrero 2019 (Rol N² 29441-2018), 3ª Sala. M: Aránguiz (r), S. Muñoz (p), Prado, Sandoval (d), Vivanco [protección].

López Palma, Felipe con Zúñiga Brito, Carolina (2019): CS, 27 febrero 2019 (Rol № 283282018), $3^{a}$ Sala. M: S. Muñoz (d), Sandoval, Aránguiz, Prado, Vivanco (d) (r) [protección].

Orellana Trincado, Oscar con Dirección General de Crédito Prendario (2019): CS, 28 febrero 2019 (Rol N² 2552-2019), 3ª Sala. M: Biel, Blanco, S. Muñoz (d), J. Muñoz (r), Vivanco [protección].

Meléndez Jiménez, Rosa Violeta con Agencia Nacional de Inteligencia (2019): CS, 11 marzo 2019 (Rol N²2174-2018), $3^{\text {a }}$ Sala. M: S. Muñoz (d), Prado (r) (d), Sandoval; Al: De La Maza, Pierry [protección].

Durán Bravo, Maribel con Servicio de Registro Civil e Identificación (2019): CS, 11 marzo 2019 (Rol N² 234-2019), 3a Sala. M: S. Muñoz (d), Sandoval, Vivanco (d); Al: Pierry (p), Quintanilla (r) [protección].

Arrepol Barra, Marcelo con Subsecretaría del Interior (2019): CS, 11 marzo 2019 (Rol N 241-2019), $3^{a}$ Sala. M: S. Muñoz (d), Sandoval, Vivanco (d); Al: Quintanilla (r), Pierry [protección].

Soto Morán, Ximena con Servicio Nacional de Menores (2019): CS, 12 marzo 2019 (Rol No 32953-2018), $3^{a}$ Sala. M: Aránguiz, Prado, Sandoval, Vivanco; Al: Pierry (r) [protección].

Hohmann Toledo, Enrique con Secretaría Regional Ministerial de Educación Los Lagos (2019): CS, 12 marzo 2019 (Rol N 32723-2018), 3a Sala. M: Aránguiz (d), S. Muñoz (p), Prado, Sandoval (d); Al: Gómez (r) [protección].

Roa Cerda, Cristhian con Dirección de Obras Hidráulicas (2019): CS, 12 marzo 2019 (Rol $N^{\circ}$ 1319-2019), $3^{a}$ Sala. M: Biel, Blanco, J. Muñoz (r), Vivanco; Al: Pallavicini [protección].

Fernández Carrera, Karina Angélica con Subsecretaría de Evaluación Social (2019): CS, 13 marzo 2019 (Rol N² 29757-2018), $3^{a}$ Sala. M: Prado, Sandoval (d), Vivanco; Al: Pierry (d), Quintanilla (r) [protección].

Segura Domínguez, Renato con Dirección General de Relaciones Económicas Internacionales (2019): CS, 14 marzo 2019 (Rol No 24594-2018), 3ª Sala. M: Sandoval, Prado, Vivanco; Al: Munita (r), Pierry (p) [protección].

Muñoz González, Jaime con Servicio de Vivienda y Urbanismo de la Región del Maule (2019): CS. 21 marzo 2019 (Rol No 22181-2018), 3a Sala. M: Sandoval (r) (d), Prado, Vivanco; Al: Etcheberry, Munita [protección].

Pojomovsky De la Carrera, Valentina con Instituto Nacional de la Juventud (2019): CS, 25 marzo 2019 (Rol No 23027-2018), 3ª Sala. M: S. Muñoz (d), Sandoval (r), Aránguiz, Prado, Vivanco (p) [protección].

Ramírez Cornejo, Miguel con Gobierno Regional Arica y Parinacota (2019): CS, 25 marzo 2019 (Rol N 2512-2019), 3a Sala. M: S. Muñoz (d), Blanco, Vivanco (r), Biel, J. Muñoz [protección].

Torres Pastene, Dayana con Servicio de Vivienda y Urbanismo (2019): CS, 22 marzo 2019 (Rol No 26441-2018), $3^{\text {a }}$ Sala. M: S. Muñoz (p), Sandoval (d), Prado, Vivanco (r); Al: Munita [protección].

Carrasco González, Fabiola con Servicio de Vivienda y Urbanismo de la Región de la Araucanía (2019): CS, 26 marzo 2019 (Rol No 26437-2018), 3a Sala. M: S. Muñoz (p), Prado, Sandoval (d), Vivanco (r); Al: Munita [protección]. 
Alvarez González, Mary Triny con Secretaría Regional Ministerial de Educación y otro (2019): CS, 28 marzo 2019 (Rol N²891-2019), 3a Sala. M: S. Muñoz (d), Blanco, Prado, Vivanco, Biel (r) [protección].

Escudey Godoy, Caludio con Hospital Base de Osorno (2019): CS, 4 abril 2019 (Rol No 4079-2019), $3^{a}$ Sala. M: S. Muñoz (d), Sandoval, Blanco, Prado (r), Vivanco [protección].

Zapata Urzúa, Juan con Servicio de Salud Atacama (2019): CS, 8 abril 2019 (Rol Nº 39142019), $3^{a}$ Sala. M: S. Muñoz (d), Sandoval (r), Blanco, Prado, Vivanco [protección].

Leiva Montecinos, Daniela con Servicio Nacional de Capacitación y Empleo (2019): CS, 8 abril 2019 (Rol No 3867-2019), 3a Sala. M: S. Muñoz (d), Sandoval, Blanco (r) (d), Prado, Vivanco [protección].

Mazuela Águila, Claudia con Gobierno Regional de Los Lagos (2019): CS, 8 abril 2019 (Rol No 4212-2019), $3^{a}$ Sala. M: S. Muñoz (r) (d), Sandoval, Prado, Vivanco; Al: Quintanilla [protección].

Alegría Osorio, Mauricio con Instituto de Desarrollo Agropecuario (2019): CS, 10 abril 2019 (Rol No 3640-2019), 3a Sala. M: Blanco, S. Muñoz (r) (d), Prado, Sandoval, Vivanco [protección].

Fuentes Flores, Roberto Antonio con Junta Nacional de Jardines Infantiles A (2019): CS, 14 abril 2019 (Rol No 3682-2019), $3^{a}$ Sala. M: Blanco, S. Muñoz (d), Prado, Sandoval (r), Vivanco [protección].

Aguilera Cuadra, Nevenka con Subsecretaría del Interior (2019): CS, 16 abril 2019 (Rol $N^{\circ}$ 3683-2019), $3^{a}$ Sala. M: Blanco, S. Muñoz (d), Prado, Sandoval (r), Vivanco [protección].

Torres González, Paola con Instituto de Desarrollo Agropecuario (2019): CS, 22 abril 2019 (Rol N 5556-2019), 3a Sala. M: S. Muñoz (d) (r), Sandoval, Vivanco; Al: Quintanilla, PaIlavicini [protección].

Oyarzun Albarracín, Marcelo con Junta Nacional de Auxilio Escolar y Becas (2019): CS, 22 abril 2019 (Rol No 7581-2019), $3^{\text {a }}$ Sala. M: S. Muñoz (p), Prado, Sandoval, Vivanco; Al: Pallavicini (d) (sr) [protección].

Hermosilla Jaque, Juan con Instituto de Desarrollo Agropecuario (2019): CS, 22 abril 2019 (Rol No 7659-2019), $3^{a}$ Sala. M: S. Muñoz (p), Prado, Sandoval, Vivanco; Al: Pallavicini (d) (sr) [protección].

Rodríguez Cárdenas, Claudia con Instituto de Desarrollo Agropecuario (2019): CS, 22 abril 2019 (Rol N 5557-2019), 3ª Sala. M: S. Muñoz (r) (d), Sandoval, Vivanco; Al: Pallavicini, Quintanilla [protección].

Vargas Arriagada, María con Servicio de Vivienda y Urbanismo de la Región de la Araucanía (2019): CS, 24 abril 2019 (Rol No 33017-2018), $3^{a}$ Sala. M: S. Muñoz (p), Sandoval (d), Vivanco (r); Al: Etcheberry, Pallavicini (d) [protección].

Castillo Vega, Cristian Roberto con Ministerio de Desarrollo Social (2019): CS, 24 abril 2019 (Rol No 5110-2019), $3^{a}$ Sala. M: Blanco, S. Muñoz (d), Prado, Sandoval, Vivanco (r) [protección].

Álvarez Aguirre, Juan Pablo con Superintendencia de Educación de la Región de Magallanes y Antártica Chilena (2019): CS, 29 abril 2019 (Rol N 6849-2019), 3ª Sala. M: Aránguiz (d), Sandoval, Vivanco; Al: Munita, Quintanilla (r)[protección]

Varela Villagrán, Jaime con Servicio Nacional para la Prevención y Rehabilitación del Consumo de Drogas y Alcohol (2019): CS, 8 mayo 2019 (Rol N² 2824-2019), $3^{a}$ Sala. M: S. Muñoz (d), Sandoval, Blanco, Prado, Vivanco (r) [protección].

Morales Correa, César con Ministerio de Salud (2019): CS, 8 mayo 2019 (Rol № 51682019), $3^{a}$ Sala. M: Blanco, S. Muñoz (d), Prado, Sandoval, Vivanco (r) [protección].

Cruces Pérez, Paula Inés con Gobierno Regional de Aysén (2019): CS, 13 mayo 2019 (Rol N 5457-2019), $3^{a}$ Sala. M: S. Muñoz, Prado, Sandoval (p), Vivanco; Al: Gómez [protección].

Moya Muñoz, Patricio Eduardo con Subsecretaría del Interior (2019): CS, 13 mayo 2019 (Rol N5287-2019), $3^{a}$ Sala. M: S. Muñoz (r) (d), Prado, Sandoval, Vivanco; Al: Gómez [protección] 
Ascencio Vidal, Miguel con Junta Nacional de Auxilio Escolar y Becas (2019): CS, 13 mayo

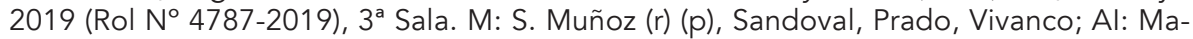
tus (p) [protección].

Contreras Poyanco, Marcia Elena con Ministerio del Interior (2019): CS, 13 mayo 2019 (Rol No 4656-2019), $3^{\text {a }}$ Sala. M: S. Muñoz (r) (d), Prado, Sandoval, Vivanco; Al: Matus [protección].

Pavez Gómez, Myrna con Servicio Nacional de la Mujer y Equidad de Género (2019): CS, 14 mayo 2019 (Rol No 5733-2019), 3ª Sala. M: S. Muñoz, Sandoval (p), Prado, Vivanco (r); Al: Pallavicini (d) [protección].

Ganga Urbina, Gloria con Ministerio de Obras Públicas (2019): CS, 14 mayo 2019 (Rol N 5895-2019), $3^{a}$ Sala. M: S. Muñoz (p), Prado, Sandoval (d), Vivanco (r); Al: Pallavicini (d) [protección].

Pereira Gajardo, Karen Elizabeth con Subsecretaría del Interior (2019): CS, 15 mayo 2019 (Rol No 7334-2019), $3^{\text {a }}$ Sala. M: Aránguiz (r) (p), S. Muñoz (p), Prado (d), Sandoval (d), Vivanco [protección].

Cárdenas Pinto, Oriana con Servicio de Vivienda y Urbanización (2019): CS, 15 mayo 2019 (Rol No 7295-2019), $3^{a}$ Sala. M: S. Muñoz (p), Sandoval (r), Prado, Vivanco; Al: Pallavicini (d) [protección].

Medel Retamal, Blanca con Servicio Nacional del Adulto Mayor (2019): CS, 15 mayo 2019 (Rol No 24719-2018), $3^{a}$ Sala. M: S. Muñoz (p), Sandoval (d), Prado (r), Vivanco; Al: Munita [protección].

Quiroz Valenzuela, Víctor Mauricio con Hospital Base de Osorno (2019): CS, 27 mayo 2019 (Rol N 4213-2019), $3^{\text {a }}$ Sala. M: Blanco, S. Muñoz (r) (d), Prado, Sandoval, Vivanco [protección].

Rey Pinto, Cynthia Carolina con Servicio de Salud O'Higgins (2019): CS, 27 mayo 2019 (Rol $N^{\circ}$ 2802-2019), $3^{a}$ Sala. M: Biel, Blanco, S. Muñoz, Prado (r) (p), Vivanco [protección].

Barría Angulo, Bernardo René con Instituto Nacional de la Juventud (2019): CS, 27 mayo 2019 (Rol N 5906-2019), $3^{a}$ Sala. M: S. Muñoz (p), Prado (r), Sandoval (d), Vivanco; Al: Pallavicini (d) [protección].

Silva Zamorano, Juan con Servicio de Salud de Concepción (2019): CS, 28 mayo 2019 (Rol No 6095-2019), $3^{\text {a }}$ Sala. M: S. Muñoz (d), Sandoval, Prado (r), Vivanco; Al: Pallavicini [protección].

Cabrera Leal, Catherine con Servicio Nacional de Capacitación y Empleo (2019): CS, 28 mayo 2019 (Rol No 6000-2019), 3ª Sala. M: S. Muñoz (d), Prado (r), Sandoval, Vivanco; Al: Pallavicini [protección]

Cancino Cáceres, Eduardo con Instituto Nacional de Desarrollo Agropecuario (2019): CS, 29 mayo 2019 (Rol No 6833-2019), $3^{a}$ Sala. M: Sandoval, Aránguiz ( $p$ ), Vivanco; Al: Quintanilla, Munita (r) [protección].

De la Fuente Alvarez, Ana María Isabel con Instituto Nacional de Desarrollo Agropecuario (2019): CS, 29 mayo 2019 (Rol N 6832-2019), 3ª Sala. M: Aránguiz (precariedad), Sandoval (d), Vivanco; Al: Munita (r), Quintanilla [protección].

Jerez Vidal, Marta Paulina con Superintendencia de Educación (2019): CS, 3 junio 2019 (Rol No 6269-2019), $3^{a}$ Sala. M: S. Muñoz (d), Prado, Sandoval, Vivanco; Al: Pallavicini (r) [protección].

Rondón Humeres, Álvaro con Fondo de Solidaridad e Inversión Social (2019): CS, 3 junio 2019 (Rol No 5499-2019), 3a Sala. M: S. Muñoz (r) (p), Sandoval (d), Prado; Al: Pierry, Etcheberry [protección].

Duarte Flores, Jorge con Instituto de Desarrollo Agropecuario (2019): CS, 11 junio 2019 (Rol No 4817-2019), $3^{\text {a }}$ Sala. M: S. Muñoz (r) (d), Prado, Sandoval, Vivanco; Al: Matus [protección].

Barahona León, Fabián con Instituto de Desarrollo Agropecuario (2019): CS, 11 junio 2019 (Rol No 4803-2019), $3^{\text {a }}$ Sala. M: S. Muñoz (r) (d), Sandoval (d), Prado, Vivanco; Al: Matus (d) [protección]. 
Miranda Delgado, Alejandra con Subsecretaría de Servicios Sociales (2019): CS, 17 junio 2019 (Rol No 20494-2018), 3ª Sala. M: Biel, Blanco, S. Muñoz (r), J. Muñoz, Vivanco [protección].

Fuentes Reyes, Jorge con Fondo de Solidaridad e Inversión Social (2019): CS, 3 julio 2019 (Rol No 3404-2019), $3^{a}$ Sala. M: S. Muñoz (p), Sandoval (d), Blanco, Prado, Vivanco (r) [protección].

Peña Castro, Claudia con Servicio Nacional de Capacitación y Empleo (2019): CS, 9 julio 2019 (Rol N 7325-2019), 3ª Sala. M: S. Muñoz (r) (p), Sandoval (d), Prado, Vivanco; Al: Pallavicini (d) [protección].

Berger Salinas, Maureen con Junta Nacional de Auxilio Escolar y Becas (2019): CS, 24 julio 2019 (Rol N 16103-2019), 3ª Sala. M: Sandoval (d), Fuentes, J. Muñoz (r); Al: QuintaniIla, Munita [protección].

González Gelvez, Rita con Servicio Nacional para la Prevención y Rehabilitación del Consumo de Drogas y Alcohol (2019): CS, 11 septiembre 2019 (Rol No 12309-2019), 3a Sala. M: Sandoval, Dahm, Silva (p); Al: Quintanilla, Pallavicini (r) (d) [protección].

Varela Campos, Daniela con Gobierno Regional Metropolitano de Santiago (2019): CS, 11 septiembre 2019 (Rol No 12294-2019), 3a Sala. M: Sandoval, Dahm, Silva (p); Al: Quintanilla, Pallavicini (r) (d) [protección].

Valenzuela Mejías, Pablo y otros con Instituto Nacional del Deporte (2019): CS, 24 septiembre de 2019 (Rol No 11502-2019), 3ª Sala. M: S. Muñoz (p), Sandoval (d), Aránguiz (p), Prado (r), Vivanco [protección].

Seguel Jara, Ramón con Universidad de Santiago (2019): CS, 27 septiembre 2019 (Rol $N^{\circ}$ 13307-2019), $3^{a}$ Sala. M: S. Muñoz (p), Sandoval (d), Vivanco; Al: Quintanilla (r), Etcheberry [protección].

Araya Valdés, Rubén con Servicio Nacional de Menores (2019): CS, 2 octubre 2019 (Rol No 12536-2019), $3^{a}$ Sala. M: S. Muñoz (p), Sandoval (d), Vivanco; Al: Quintanilla (r), Etcheberry [protección].

Corveleyn Castro, Jorge con Municipalidad de Talca (2019): CS, 2 octubre 2019 (Rol $N^{\circ}$ 12588-2019), $3^{a}$ Sala. M: S. Muñoz (p), Sandoval (d), Vivanco; Al: Quintanilla (r), Etcheberry [protección].

Lamilla Canales, Zaida con Ministerio de Salud (2019): CS, 18 noviembre 2019 (Rol $N^{\circ}$ 14948-2019), $3^{\text {a }}$ Sala. M: S. Muñoz (r) (p), Sandoval (d), Vivanco, J. Muñoz; Al: Quintanilla (d) [protección].

Soto García, Patricia con Hospital de Ancud (2019): CS, 18 noviembre 2019 (Rol No 212612019), $3^{\text {a }}$ Sala. M: S. Muñoz (p) (r), Sandoval (d), Aránguiz (p),Vivanco; Al: Pallavicini (d) [protección].

Castro Flores, María con Junta Nacional de Auxilio Escolar y Becas (2019): CS, 18 noviembre 2019 (Rol N 20737-2019), 3ª Sala. M: S. Muñoz (r) (p), Sandoval (d), Aránguiz (p), Vivanco; Al: Pallavicini (d) [protección].

Ramos Navarrete, Gabriel con Servicio de Vivienda y Urbanismo de la Región de Valparaíso (2019): CS, 28 noviembre 2019 (Rol N²0916-2019), 3a Sala. M: S. Muñoz (p) (r), Sandoval (d), Aránguiz, Vivanco; Al: Pallavicini (d) [protección].

Ivanovic Willumsen, Catalina con Secretaría Regional Ministerial de Salud de la Región de Los Lagos (2019): CS, 20 noviembre 2019 (Rol N 31353-2018), $3^{\text {a }}$ Sala. M: S. Muñoz (p), Sandoval (d), Fuentes, Prado (r) (p), Gómez [protección].

Jadue Jadue, Solange con Dirección de Compras y Contratación Pública (2019): CS, 25 noviembre 2019 (Rol No 16914-2019), 3ª Sala. M: Sandoval (d), Fuentes, J. Muñoz (r); Al: Quintanilla, Munita [casación].

Torca Merino, Cristóbal Francisco con Gobierno Regional de la Araucanía (2019): CS, 3 diciembre 2019 (Rol N 33500-2019), 3a Sala. M: S. Muñoz, Sandoval (d), Aránguiz, Vivanco; Al: Pallavicini (d) (sr) [protección].

Contreras Pardo, Yasna y Flores Chirre, Jaime con Corporación Administrativa del Poder Judicial (2019): CS, 4 diciembre 2019 (Rol No 15977-2019), 3a Sala. M: S. Muñoz (r), Sandoval (d), Aránguiz, Vivanco; Al: Pallavicini (d) [protección]. 
Pávez Carrasco, Haydee con Secretaría Regional Ministerial de Educación de la Región Metropolitana (2019): CS, 12 diciembre 2019 (Rol N 18445-2019), 3a Sala. M: S. Muñoz, Sandoval, J. Muñoz; Al: Abuauad (r), Pallavicini (d) [protección].

Zamorano Vargas, María Paz con Gobierno Regional Metropolitano de Santiago (2019): CS, 12 diciembre 2019 (Rol N 18440-2019), $3^{\text {a }}$ Sala. M: S. Muñoz (d), Sandoval, J. Muñoz; Al: Abuauad (r), Pallavicini [protección].

Lagos Jara, Raquel Olivia con Gobierno Regional de la Araucanía (2019): CS, 12 diciembre 2019 (Rol N 17643-2019), $3^{a}$ Sala. M: S. Muñoz (d), Vivanco, J. Muñoz; Al: Pierry, Pallavicini (r) [protección].

Escobar Villagra, María con Servicio de Vivienda y Urbanización de la Región de la Araucanía (2019): CS, 12 diciembre 2019 (Rol No 17641-2019), 3ª Sala. M: S. Muñoz (d), Vivanco, J. Muñoz; Al: Pierry, Pallavicini (r) [protección].

Sepúlveda Maldonado, Juan Carlos con Servicio Nacional de Menores (2019): CS, 12 diciembre 2019 (Rol № 17619-2019), 3a Sala. M: S. Muñoz, Vivanco, J. Muñoz; Al: Pierry (d), Pallavicini (r) (d) [protección].

Colihuil Binimelis, José con Subsecretaría de Desarrollo Regional y Administrativo (2019): CS, 12 diciembre 2019 (Rol N 17466-2019), 3ª Sala. M: S. Muñoz (d), Vivanco, J. Muñoz; Al: Pierry, Pallavicini (r) [protección].

García Lastarria, Miguel con Ministerio Secretaría General de Gobierno (2019): CS, 12 diciembre 2019 (Rol No 15478-2019), 3ª Sala. M: S. Muñoz, Vivanco, J. Muñoz; Al: Pierry (d), Pallavicini (d) (r) [protección].

Latin Quezada, Renán con Subsecretarría de Salud Pública (2019): CS, 12 diciembre 2019 (Rol No 15458-2019), $3^{\text {a }}$ Sala. M: S. Muñoz, Vivanco, J. Muñoz; Al: Pierry, Pallavicini (d) (r) [protección].

Simonet Romero, Romina Paz con Ministerio de la Mujer y Equidad de Género (2019): CS, 12 diciembre 2019 (Rol No 14812-2019), 3a Sala. M: S. Muñoz (p), Vivanco, J. Muñoz; Al: Pierry (d), Pallavicini (d) (r) [protección].

Espinoza Gavilán, Sergio con Subsecretaría de Desarrollo Regional y Administrativo (2019): CS, 12 diciembre 2019 (Rol No 18732-2019), 3a Sala. M: S. Muñoz (d), Sandoval, J. Muñoz; Al: Abuauad (r), Pallavicini [protección].

González Nahum, Óscar con Servicio de Vivienda y Urbanización de la Región de la Araucanía (2019): CS, 12 diciembre 2019 (Rol No 18639-2019), 3ª Sala. M: S. Muñoz (d), Sandoval, Vivanco; Al: Lagos (r), Barra [protección].

Valdebenito Solís, Cristian con Instituto de Desarrollo Agropecuario (2019): CS, 17 diciembre 2019 (Rol No 23210-2019), 3a Sala. M: S. Muñoz (d), Sandoval, Repettto (d); Al: Quintanilla, Pierry (r) [protección].

Álvarez Catalán, Claudio con Fondo de Solidaridad e Inversión Social (2019): CS, 17 diciembre 2019 (Rol No 23182-2019), $3^{\text {a }}$ Sala. M: S. Muñoz (d), Sandoval, Repettto (d); Al: Quintanilla, Pierry (r) [protección].

Nieto Navarrete, Gloria con Secretaría Regional Ministerial del Deporte de la Región de la Araucanía (2019): CS, 17 diciembre 2019 (Rol No 23058-2019), 3a Sala. M: S. Muñoz (d), Sandoval, Repettto (d); Al: Quintanilla, Pierry (r) [protección].

Torres Zalazar, Juan Manuel con Junta Nacional de Auxilio Escolar y Becas (2019): CS, 18 diciembre 2019 (Rol No 16982-2019), 3ª Sala. M: S. Muñoz (p), Vivanco, J. Muñoz; Al: Pierry (d), Pallavicini (d) (r) [protección].

Muñoz Riveros, Héctor José con Gobierno Regional Metropolitano (2019): CS, 19 diciembre 2019 (Rol No 17756-2019), 3a Sala. M: S. Muñoz (p), Sandoval (d) (r), Vivanco, J. Muñoz; Al: Pallavicini [protección].

Martínez Rojas, Raúl Roger con Servicio Local de Educación de Puerto Cordillera (2019): CS, 19 diciembre 2019 (Rol No 17321-2019), 3a Sala. M: S. Muñoz, Sandoval (d) (r), Vivanco; Al: Abuauad (r), Pierry (d) [protección].

Paredes Toledo, Marcela con Servicio Nacional de la Mujer y de la Equidad de Género (2019): CS, 19 diciembre 2019 (Rol No 15452-2019), 3a Sala. M: S. Muñoz, Sandoval (d), Aránguiz (r); Al: Lagos, Gómez [protección]. 
16. Regularización de derechos de aguas [4 casos]

Esval S.A con Meyer Vorlaeufer, Hella I (2019): CS, 13 marzo 2019 (Rol No 8470-2018), 3a Sala. M: Sandoval, Vivanco, Biel (d) (r); Al: Gajardo (d), Pallavicini [casación]

Esval S.A con Meyer Vorlaeufer, Hella II (2019): CS, 13 marzo 2019 (Rol No 8471-2018), 3a Sala. M: Sandoval, Vivanco, Biel (d) (r); Al: Gajardo (d), Pallavicini [casación]

Moreno Verdugo Aldo con Junta de Vigilancia Estero Chimbarongo (2019): CS, 30 mayo 2019 (Rol No 19224-2018), $3^{a}$ Sala. M: S. Muñoz, Blanco, Prado (d), Vivanco (r); Al: Munita (d) [casación].

Lay Son Román, Gladys con Aguas del Altiplano S.A (2019): CS, 9 julio 2019 (Rol N 154842018), 3a Sala. M: S. Muñoz, Blanco, Vivanco (r), Biel; Al: Pierry (d) [casación]

18. Plazo para que tercero absoluto pueda solicitar invalidación ambiental [1 caso]

Comunidad Agrícola La Dormida con Servicio de Evaluación Ambiental (2019): CS, 7 noviembre 2019 (Rol No 7073-2019), 3a Sala. M: S. Muñoz, Sandoval, Aránguiz, Vivanco; Al: Quintanilla (sr) [casación]. 